\title{
Neuromuscular Ultrasound: Clinical Applications and Diagnostic Values
}

\author{
Jean K. Mah, Nens van Alfen
}

\begin{abstract}
Advances in high-resolution ultrasound have provided clinicians with unique opportunities to study diseases of the peripheral nervous system. Ultrasound complements the clinical and electrophysiology exam by showing the degree of abnormalities in myopathies, as well as spontaneous muscle activities in motor neuron diseases and other disorders. In experienced hands, ultrasound is more sensitive than MRI in detecting peripheral nerve pathologies. It can also guide needle placement for electromyography exam, therapeutic injections, and muscle biopsy. Ultrasound enhances the ability to detect carpal tunnel syndrome and other focal nerve entrapment, as well as pathological nerve enlargements in genetic and acquired neuropathies. Furthermore, ultrasound can potentially be used as a biomarker for muscular dystrophy and spinal muscular atrophy. The combination of electromyography and ultrasound can increase the diagnostic certainty of amyotrophic lateral sclerosis, aid in the localization of brachial plexus or peripheral nerve trauma and allow for surveillance of nerve tumor progression in neurofibromatosis. Potential limitations of ultrasound include an inability to image deeper structures, with lower sensitivities in detecting neuromuscular diseases in young children and those with mitochondrial myopathies, due to subtle changes or early phase of the disease. As well, its utility in detecting critical illness neuromyopathy remains unclear. This review will focus on the clinical applications of neuromuscular ultrasound. The diagnostic values of ultrasound for screening of myopathies, neuropathies, and motor neuron diseases will be presented.
\end{abstract}

RÉSUMÉ: Applications cliniques et valeurs diagnostiques des examens d'échographie destinés aux maladies neuromusculaires. Les progrès réalisés en matière d'examens d'échographie haute résolution offrent aux cliniciens d'uniques possibilités d'étudier les maladies du système nerveux périphérique. En permettant d'observer l'étendue des anomalies liées aux myopathies de même que l'activité musculaire spontanée dans des cas de maladies motoneuronales et d'autres troubles, ces examens représentent ainsi un complément aux examens cliniques et électro-physiologiques. Entre des mains expérimentées, la capacité de ces examens à détecter des pathologies du système nerveux central dépasse celle d'un appareil d'IRM. Ils permettent aussi d'orienter le positionnement d'une seringue lors d'un examen d'électromyographie, d'une injection thérapeutique et d'une biopsie musculaire. Il faut également noter qu'ils améliorent la capacité de détection du syndrome du canal carpien et des autres problèmes de compression focale des nerfs mais aussi celle des signes cliniques d'élargissement des nerfs qui sont le propre de neuropathies génétiques et acquises. Qui plus est, ils peuvent potentiellement être utilisés à titre de biomarqueurs dans des cas de dystrophie musculaire et d'amyotrophie spinale. Ainsi, le fait de combiner des examens d'électromyographie et des examens d'échographie peut accroître l'exactitude diagnostique de cas de sclérose latérale amyotrophique (SLA), aider à la localisation de traumatismes du système nerveux périphérique ou du plexus brachial et permettre de surveiller la progression tumorale affectant les nerfs dans des cas de neurofibromatose. Il existe toutefois de possibles limites quant à l'utilisation des examens d'échographie, par exemple l'impossibilité de rendre par images des structures plus profondes ou de détecter, avec des niveaux inférieurs de sensibilité, des maladies neuromusculaires ou des myopathies mitochondriales chez des jeunes enfants, le tout pouvant être attribué à une évolution subtile de ces maladies ou au fait qu'elles en soient encore à une phase précoce. De plus, l'utilité de ces examens dans le cas de neuromyopathies graves demeure vague. Cette étude entend donc mettre l'accent sur les applications cliniques des examens d'échographie neuromusculaire. Les valeurs diagnostiques de ces examens en vue de dépister des cas de myopathie, de neuropathie et de maladies motoneuronales seront également présentées.

Keywords: Neuromuscular disorders, Ultrasound, Neurological practice

doi:10.1017/cjn.2018.314

Can J Neurol Sci. 2018; 45: 605-619

\section{INTRODUCTION}

High-resolution ultrasound is a novel non-invasive tool that is increasingly used to screen, diagnose, and facilitate the treatment of patients with suspected neurologic disorders. In particular, it has been used as part of a comprehensive evaluation of neuromuscular diseases. Such an approach requires the integration of clinical assessments, electrodiagnostic tests, neuroimaging, pathology, and laboratory investigations including targeted genetic testing. Muscle and nerve imaging complements the clinical and electrophysiology exam by accurately depicting the specific area or pattern of abnormalities, allowing direct

From the Departments of Pediatrics and Clinical Neurosciences, Alberta Children's Hospital Research Institute, Cumming School of Medicine, University of Calgary, Calgary, Alberta, Canada (JKM); Department of Neurology and Clinical

Neurophysiology, Donders Institute for Brain, Cognition and Behaviour, Radboud University Medical Center, Nijmegen, The Netherlands (NvA).

Received January 7, 2018. Final Revisions Submitted May 19, 2018. Date of ACCEPTANCE June 24, 2018.

Correspondence to: J. K. Mah, Alberta Children's Hospital, 2888 Shaganappi Trail NW, Calgary, AB, Canada T3B 6A8. Email: jkmah@ucalgary.ca 
visualization of spontaneous muscle movements, as well as monitoring for other associated pathologies.

In the early years of neuromuscular imaging (1985-2000), muscle computed tomography (CT) was developed as a tool to scan the whole body in search of decreased tissue density caused by fatty degeneration that would point to a pattern of involvement in a specific myopathy or neuropathy. ${ }^{1,2,3}$ However, CT has two main drawbacks, including low-tissue resolution and the use of ionizing radiation that make it a less desirable option since more patient-friendly, high-resolution techniques including highfrequency neuromuscular ultrasound and magnetic resonance myography and neurography have become available. ${ }^{4,5}$

MRI of muscle or nerve can accurately depict tissue size, texture, composition, organization, and anatomical context, both in superficial and deep body layers. It can either create a large overview of body regions to help search for a pattern of muscle involvement, ${ }^{6,7}$ or can very focally depict specific tissue changes within a certain body region to look for atrophy, fatty degeneration, edema, inflammation, morphological or tissue texture changes, and continuity. ${ }^{7-9}$ Both visual evaluation and quantified measurement, for example, of fat fractions or nerve size, are possible. The main drawbacks of MRI seem to be the limited availability of the necessary dedicated protocols, software or coils at many centers, and the need for sedation in young children or claustrophobic patients.

Ultrasound is a feasible alternative to MRI for neuromuscular imaging of superficial structures; it is a portable and readily available technology that can be used in children and adults. Recent studies have shown that neuromuscular ultrasound can reliably screen for myopathies and neuropathies, can help provide a more certain diagnosis of amyotrophic lateral sclerosis (ALS) at the time of presentation, and can be used as a non-invasive biomarker for treatment trials in muscular dystrophy and other neuromuscular diseases. ${ }^{10-15}$ This review will focus on the clinical applications of neuromuscular ultrasound. It offers added diagnostic values that adult and pediatric neurologists, clinical neurophysiologists, and other specialists can use for patient-friendly, point of care imaging of muscles and nerves.

\section{Practical Uses of Muscle Ultrasound}

\section{As a Screening Tool for Neuromuscular Diseases}

Ultrasound is a valid and reliable diagnostic imaging technique for the evaluation of nerves and muscles. ${ }^{16} \mathrm{~A}$ recent systematic review based on publications from 2000 to 2014 confirmed the utility and acceptability of ultrasound for the diagnosis of pediatric skeletal muscle disorders. ${ }^{17}$ In comparison to electromyography (EMG), muscle ultrasound is better tolerated. Among 498 children with suspected neuromuscular diseases, Hellmann et $\mathrm{al}^{18}$ reported that $17 \%$ of EMG studies were suboptimal due to intolerance to pain, even though EMG was very sensitive in detecting neurogenic disorders. As well, EMG had more difficulty in detecting myopathies in young children; the sensitivity increased from $25 \%$ in infants to $91 \%$ in children above 5 years of age. ${ }^{18}$ Alternatively, MRI can visualize deeper muscles and detect changes that are indicative of disease progression in neuromuscular diseases; however, as mentioned above, MRI has a number of potential limitations, especially in the pediatric population. Furthermore, Zaidman et $\mathrm{al}^{19}$ found that nerve ultrasound was more sensitive than MRI in detecting focal neuropathies or brachial plexopathy.

The potential diagnostic benefit of muscle ultrasound was highlighted in several pediatric studies. Following an initial pilot study of 33 children, Pillen et al prospectively studied 150 (90 males, age ranged from birth to 18 years) children referred consecutively for suspected neuromuscular disorders. ${ }^{20,21}$ The presenting symptoms were muscle weakness, fatigue, myalgia, hypotonia, and motor developmental delay. A 15-minute standard muscle ultrasound protocol (see Figure 1A) including measurement of muscle thickness (MT) and echo intensity (EI) in two proximal (i.e. biceps brachii, see Figure 2; and rectus femoris, see Figure 3) and two distal (i.e. flexor carpi radialis, see Figure 4; and tibialis anterior, see Figure 5) muscles were used in this study, and the results were compared with their published pediatric normative values; ${ }^{22}$ additional investigations included EMG, biochemical and genetic evaluations, plus muscle biopsies were performed as clinically indicated. In total, 65 (43\%) patients were subsequently diagnosed with a neuromuscular disease; $54(36 \%)$ did not show any evidence of a neurogenic or myopathic disorder; and 31 (21\%) were excluded from further analysis due to inconclusive results. $^{21}$ According to Pillen et al, ${ }^{21}$ the EI of all examined muscles were found to be significantly higher in patients with neuromuscular diseases than those without. Abnormal muscle ultrasound in their study was defined by an EI $>3.5$ standard deviation (SD) in one muscle, or $>2.5 \mathrm{SD}$ in two muscles, or $>1.5 \mathrm{SD}$ in three muscles; these ultrasound criteria were associated with a sensitivity of $71 \%$ (95\% confidence interval [CI] 60\%-82\%), a specificity of $91 \%$ (CI 83\%-99\%), and a positive predictive value (PPV) of 91\% (CI 82\%-98\%) in diagnosing pediatric neuromuscular diseases. Normal muscle ultrasound in turn was defined by an EI of less than 2.0 SD in all four muscles, plus $<1.5 \mathrm{SD}$ in three muscles, and $<1.0 \mathrm{SD}$ in two muscles; these parameters were associated with a sensitivity of $91 \%$ (CI 84\%-98\%), a specificity of $67 \%$ (CI 54\%$80 \%$ ), and a negative predictive value (NPV) of $86 \%$ (CI 76\%$96 \%)^{21}$

The sensitivity of muscle ultrasound in detecting neuromuscular diseases was lower among 43 patients who were less than 3 years of age, with a false-negative rate of $25 \%$, but no false positives were found in this age group (PPV 100\%); the false negatives were seven children with early stages of neuromuscular diseases or metabolic myopathies, including one case of congenital myopathy with fibertype disproportion, two with mitochondrial cytopathies, one with Pompe disease, one with an unspecified myopathy, one with presymptomatic Duchenne muscular dystrophy (DMD), and one with early spinal muscular atrophy (SMA). ${ }^{21}$ As well, two children were presumed to be false positives, with abnormal EI on ultrasound but no other evidence of neuromuscular diseases. ${ }^{21}$ Furthermore, the authors reported in a companion study that muscle ultrasound was less sensitive $(25 \%-46 \%)$ as a screening tool in young children with mitochondrial disorders, due to only subtle structural changes in the muscles. $^{23}$

In addition, the distribution of ultrasound abnormalities as well as the pattern of muscle involvement can aid in the diagnosis of neuromuscular diseases. The common patterns of ultrasound abnormalities in specific neuromuscular disorders are summarized in Table 1. Although MT measurements showed more prominent atrophy of the lower extremities in neurogenic disorders, discrimination between neurogenic disorders and myopathies based on the degree of muscle atrophy alone had low diagnostic accuracy, with an area under the receiver operating characteristic curve of $<0.72 .^{21}$ Instead, a combined 
A

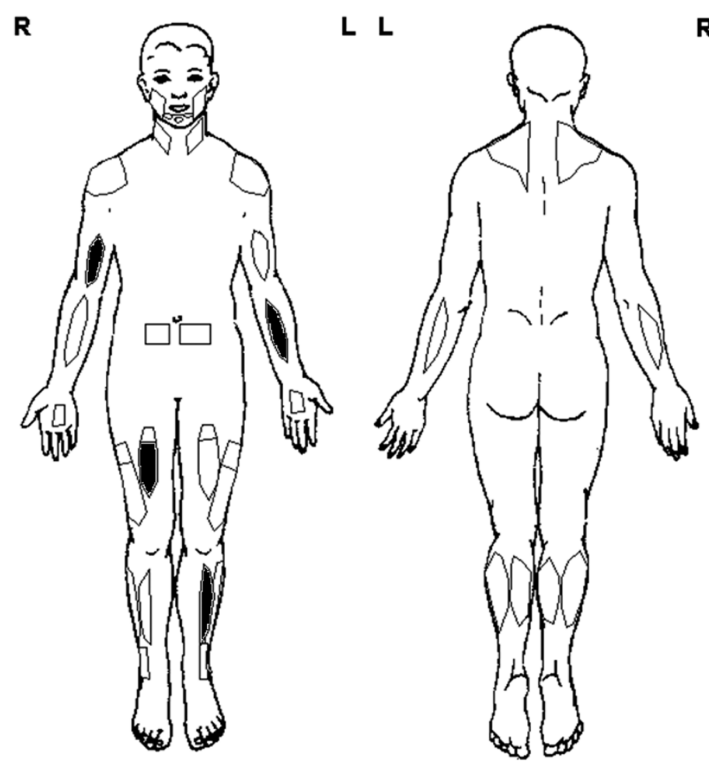

B

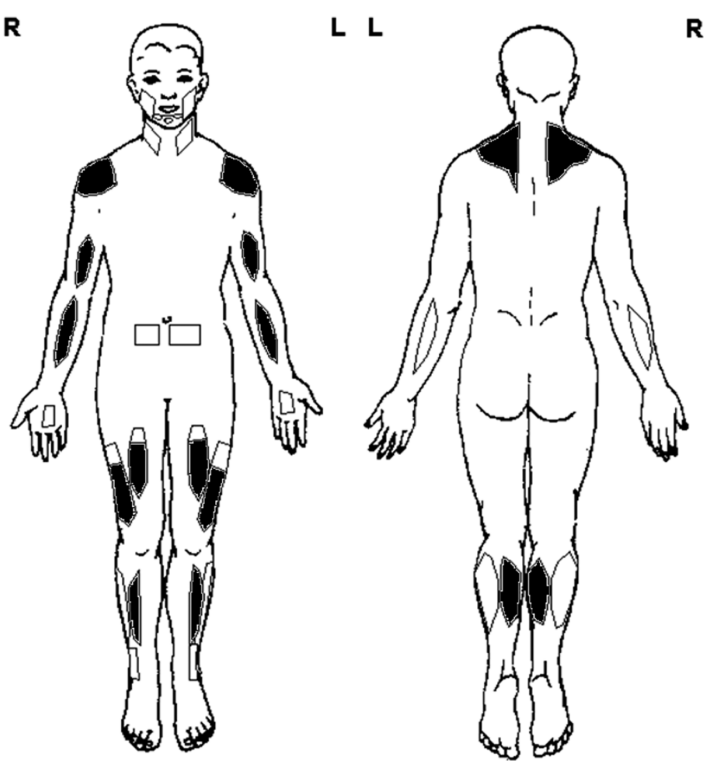

$\mathbf{C}$
$\mathbf{R}$

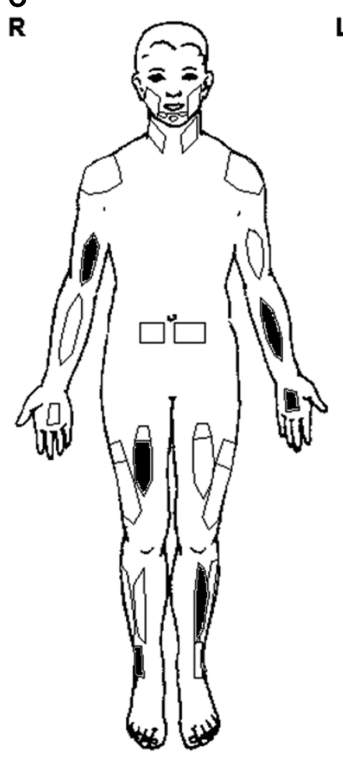

$\mathbf{L} \mathbf{L}$

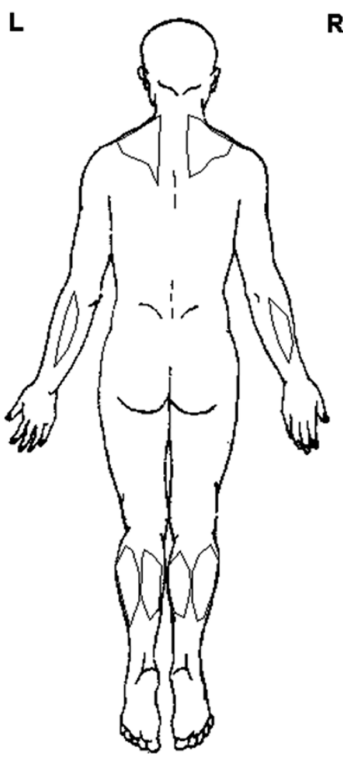

$\mathbf{R} \quad \mathbf{R}$

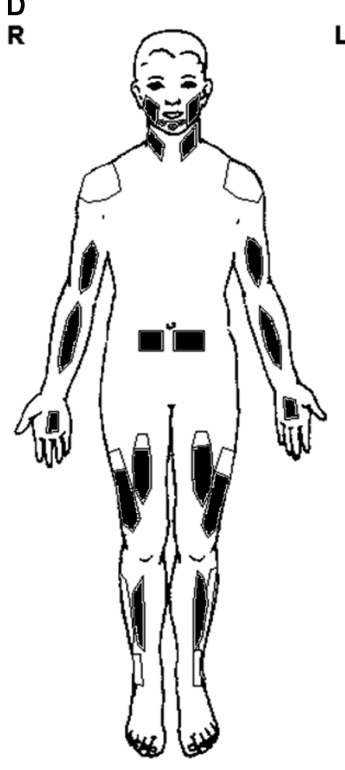

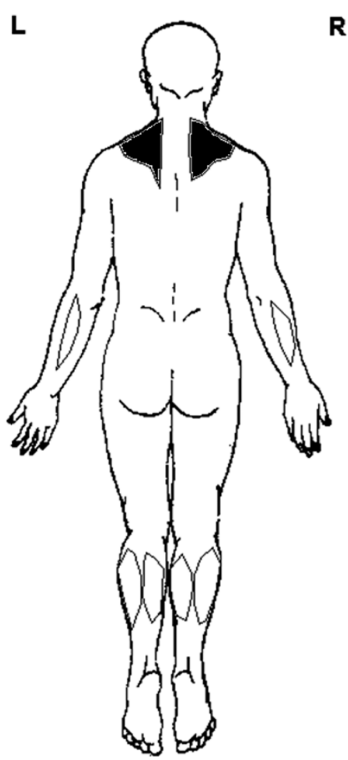

Figure 1: Basic muscle ultrasound protocol. (A) General screen-unilateral exam of the biceps brachii, flexor carpi radialis, rectus femoris, and tibialis anterior. (B) Myopathy screen-bilateral exam of the trapezius, deltoid, biceps brachii, flexor carpi radialis, rectus femoris, vastus lateralis, tibialis anterior, and medial gastrocnemius. (C) Polyneuropathy screen—general screen protocol (A) and additional exam of distal muscles such as the peroneus tertius and first dorsal interosseous. (D) Motor neuron disease screen-myopathy screen protocol $(B)$ and additional exam of rectus abdominis, sternocleidomastoid, trapezius, masseter, first dorsal interosseous, and submental muscles, plus fasciculation screening of 30-second scan time per muscle.

cut-off based on EI (increased in legs by more than 1 SD than arms) and MT (atrophy greater in legs than arms) was better at detecting neurogenic disorders, with a sensitivity of $67 \%$ (CI $49 \%-85 \%)$, a specificity of $94 \%$ (CI $87 \%-100 \%$ ), a PPV of $86 \%$ (CI $71 \%-100 \%$ ), and a NPV of $84 \%$ (CI 74\%-94\%); further discrimination of myopathies from neurogenic and non-neuromuscular disorders was limited by disease heterogeneity in the study cohort. ${ }^{21}$

Similarly, others authors have used ultrasound parameters such as muscle inhomogeneity, echogenicity, and thickness in a quantitative or qualitative approach to help differentiate between myopathies and neuropathies among adults and children with suspected neuromuscular disorders. $^{24,25,26}$ Interestingly, a recent study found that boys with DMD may not show significant muscle atrophy over the course of their disease, ${ }^{11}$ and muscle pseudo-hypertrophy can occur in both neurogenic and myopathic disorders. ${ }^{27,28}$ Both findings might explain why MT is not a very good discriminator for detecting and differentiating neuromuscular diseases.

On the other hand, selective pattern of muscle involvement can provide important diagnostic clues for the differential diagnosis of various myopathies. A systematic approach involving bilateral 


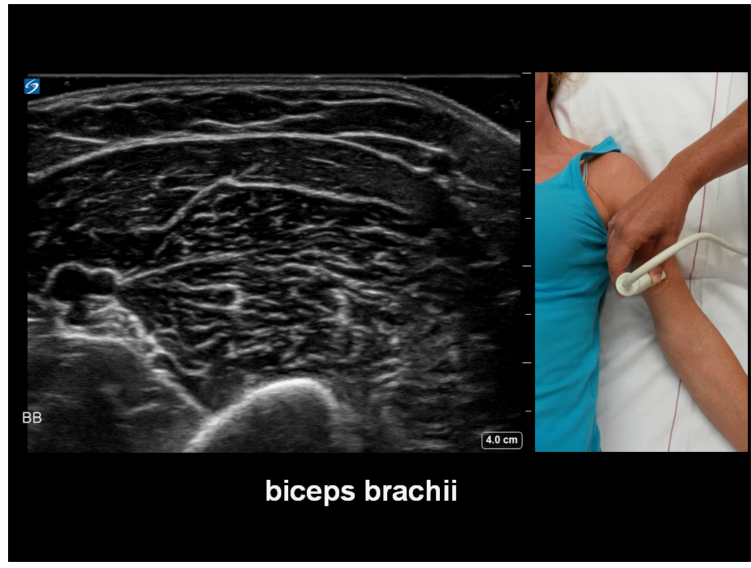

Figure 2: Muscle ultrasound image of the biceps brachii, as recorded at 2/3 of the distance from the acromion to the antecubital crease.

ultrasound exam of muscles as described in the standard ultrasound protocol, plus other proximal and distal muscles such as the trapezius, deltoid, vastus lateralis, and medial gastrocnemius are recommended as part of a myopathy screen (see Figure 1B). The presence of a peripheral rim of abnormal signal in the vastus lateralis and a central area of abnormal signal within the rectus femoris can be found in collagen VI myopathies, and early selective involvement of the rectus femoris and vastus lateralis is typically seen in RYRIrelated central core myopathies (Figure 6). ${ }^{14,29-31}$ As well, muscle ultrasound can detect a greater degree of muscle changes in patients with myotonic dystrophies and other non-dystrophic myotonic disorders, at times better than muscle MRI. ${ }^{32,33}$

\section{Improving the Diagnosis of Motor Neuron Diseases}

Ultrasound enhances the ability to detect fasciculations in $10 \%$ to $30 \%$ of muscles that may be subclinically involved or negative on EMG, thus increasing the diagnostic certainty for patients with motor neuron diseases and other neuromuscular disorders. ${ }^{34-37}$ In addition to bilateral examination of the muscles as described in the standard muscle ultrasound protocol, screening of lower motor neuron disease usually involves additional scanning of the rectus abdominis, sternocleidomastoid, trapezius, masseter, first dorsal interosseous, and

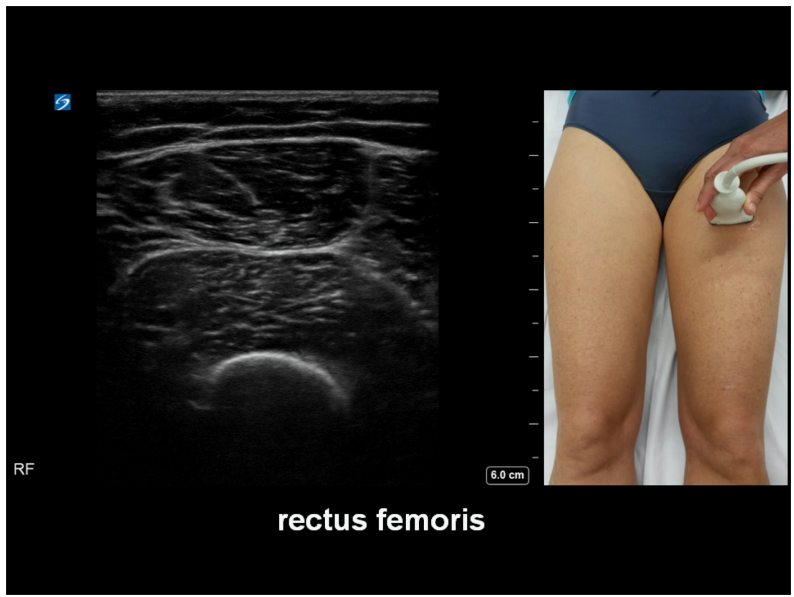

Figure 3: Muscle ultrasound of the rectus femoris, as recorded at 1/2 of the distance between the anterior superior iliac spine and the upper pole of the patella.

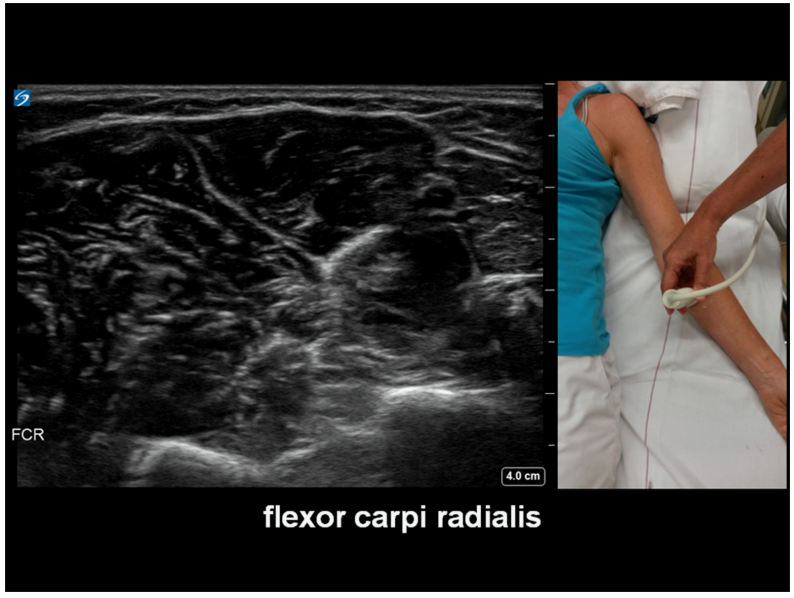

Figure 4: Muscle ultrasound of the flexor carpi radialis, as recorded at $1 / 3$ of the distance from the antecubital crease to the distal radius.

submental muscles, with fasciculation screening of up to 60-second scan time per muscle (see Figure 1D).

Arts et $\mathrm{al}^{35}$ used ultrasound as part of a cross-sectional study to examine ten muscles in each of their 48 patients with ALS and 27 patients with ALS mimics; their study found that the increase in EI was more striking than the reduction of MT in ALS. Fasciculations were identified in all but one of the 25 patients screened using a 10second scan time, with a mean of 6.5 (range 0-10) muscles showing fasciculations; the authors concluded that ultrasound could detect muscle changes during the early phase of ALS. ${ }^{35}$ In another prospective study of 59 adults with suspected ALS, muscle ultrasound was able to differentiate patients with ALS $(n=27)$ from others $(n=32)$ with ALS mimics (see example in Figures 7A-7B); the corresponding sensitivity and specificity was $96 \%$ and $84 \% .{ }^{38}$ In two recent studies, fasciculations were detected in $58 \%^{37}$ to $68 \%{ }^{39}$ of patients with ALS based on an ultrasound scan time of 10 or 60 seconds per muscle, respectively; higher sensitivities were reported when the results of ultrasound were combined with EMG. In the cranial region of ALS patients, the muscle ultrasound detection rate for fasciculations was found to be similar to that of EMG, although frequent fasciculations were again more easily detected with ultrasound. ${ }^{40}$

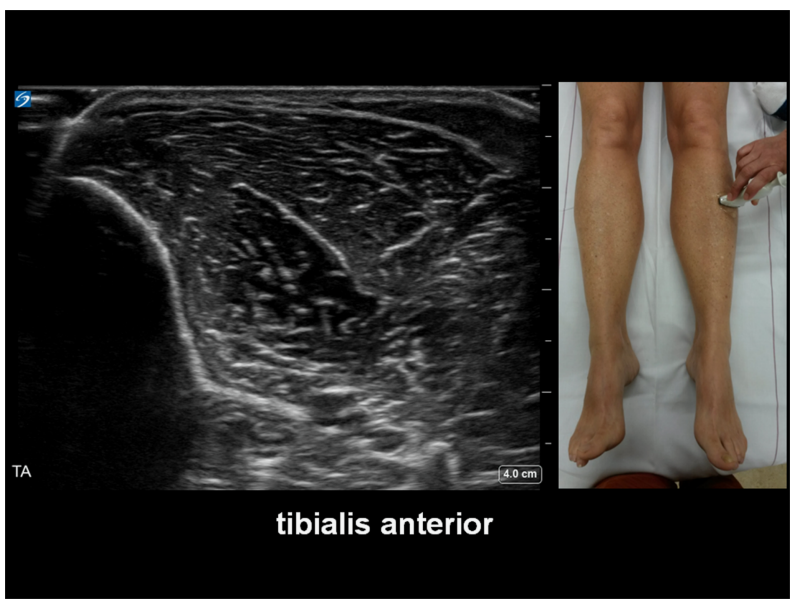

Figure 5: Muscle ultrasound of the tibialis anterior, as recorded at 1/3 of the distance from the inferior border of the patella to the lateral malleolus. 
Table 1: Common patterns of ultrasound abnormalities in neuromuscular disorders

\begin{tabular}{|c|c|c|c|}
\hline Neuromuscular diseases & $\begin{array}{l}\text { Echo } \\
\text { intensity } \\
\quad(\text { EI) }\end{array}$ & $\begin{array}{l}\text { Muscle } \\
\text { thickness (MT) }\end{array}$ & Remarks \\
\hline General & $\mathrm{N}$ to $\uparrow \uparrow \uparrow$ & $\mathrm{N}$ to $\downarrow \downarrow \downarrow$ & EI often more abnormal than MT in myopathic disorders \\
\hline \multicolumn{4}{|l|}{ Myopathies } \\
\hline Muscular dystrophies & $\uparrow \uparrow \uparrow$ & $\mathrm{N}$ to $\downarrow \downarrow$ & $\begin{array}{l}\text { Homogeneous increases in EI with "ground glass" appearance. Normal or decreased EI in deeper areas of affected } \\
\text { muscle due to increased attenuation. Preclinical cases can be normal }\end{array}$ \\
\hline Congenital myopathies & $\mathrm{N}$ to $\uparrow \uparrow \uparrow$ & $\downarrow$ to $\downarrow \downarrow$ & Homogeneous increases in EI \\
\hline Metabolic myopathies & $\mathrm{N}$ or $\uparrow$ & $\mathrm{N}$ or $\downarrow$ & Normal or mild homogeneous increases in EI \\
\hline Inflammatory myopathies & $\uparrow \uparrow$ & $\begin{array}{l}\text { Acute- }-\mathrm{N} \text { to } \uparrow \\
\text { Chronic- }-\downarrow\end{array}$ & Slight increases in EI during acute phase, more severe in chronic phase; EI is often focally increased \\
\hline Inclusion body myositis & $\uparrow \uparrow \uparrow$ & $\downarrow \downarrow$ to $\downarrow \downarrow \downarrow$ & Focal asymmetric pattern, especially in distal muscles, with increased EI in affected muscles \\
\hline \multicolumn{4}{|l|}{ Neuropathies } \\
\hline Polyneuropathy & $\uparrow$ to $\uparrow \uparrow$ & $\begin{array}{l}\downarrow \downarrow \text { in distal } \\
\text { muscles }\end{array}$ & Inhomogeneous increases in EI, distal more severe than proximal muscles \\
\hline Focal neuropathy & $\mathrm{N}$ to $\uparrow \uparrow$ & $\begin{array}{l}\downarrow \downarrow \downarrow \text { in affected } \\
\text { muscles }\end{array}$ & $\begin{array}{l}\text { First US abnormalities visible after } 10 \text { days, EI more abnormal than atrophy. Areas without reinnervation may } \\
\text { show "moth-eaten" pattern. Persistent denervation of the muscle will lead to fully white atrophic appearance } \\
\text { with now black fascial lines }\end{array}$ \\
\hline \multicolumn{4}{|l|}{ Motor neuron disease } \\
\hline Spinal muscular atrophy & $\uparrow \uparrow \uparrow$ & $\downarrow \downarrow \downarrow$ & Inhomogeneous "moth-eaten" pattern. Can be normal in very young patients \\
\hline $\begin{array}{l}\text { Amyotrophic lateral } \\
\text { sclerosis }\end{array}$ & $\uparrow \uparrow$ & $\downarrow \downarrow \downarrow$ & Fasciculations most prominent feature, EI more abnormal (increased) than atrophy \\
\hline
\end{tabular}

Modified from Pillen et al. ${ }^{124}$

$\uparrow=$ slightly increased echo intensity or muscle thickness; $\uparrow \uparrow=$ moderately increased echo intensity; $\uparrow \uparrow \uparrow=$ severely increased echo intensity; $\downarrow=$ slight atrophy; $\downarrow \downarrow=$ moderate atrophy; $\downarrow \downarrow \downarrow=$ severe atrophy; $\mathrm{N}=$ normal echo intensity or muscle thickness; US = ultrasound.

As well, among 81 adults consecutively referred for suspected ALS, Misawa et al reported that the combination of ultrasound and EMG increased the diagnostic category of probable or definite ALS from $48 \%$ (based on the revised El Escorial criteria) to $79 \%$ (based on the Awaji criteria), in part due to the enhanced ability of muscle ultrasound to detect fasciculations. ${ }^{36}$ In ALS patients who had fasciculations, a score based on the ultrasound results of nine muscles was able to discriminate between ALS and ALS mimics with 92\% sensitivity and $100 \%$ specificity. ${ }^{41}$ Other publications also confirmed the

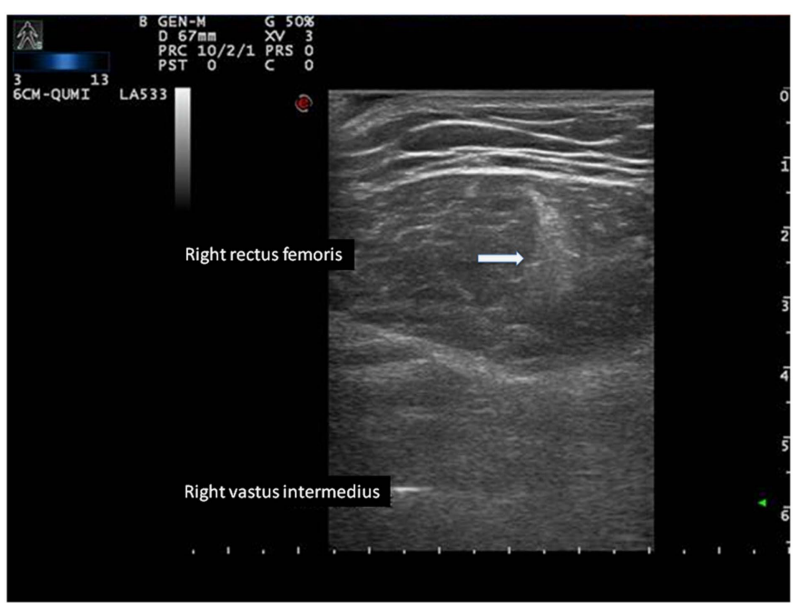

Figure 6: Transverse axis ultrasound of the quadriceps showing increased echo intensity of the rectus femoris and vastus intermedius in an adult with RYRI-related central core myopathy. utility of muscle ultrasound as part of a comprehensive assessment of patients with suspected ALS. ${ }^{37,42}$ Nerve ultrasound can also help differentiate between patients with ALS and multifocal motor neuropathy (MMN), with a sensitivity ranging from $87 \%$ to $100 \%$, and a specificity of $92 \%$ to $94 \% .^{43,44}$ Furthermore, ultrasound can potentially be used to monitor for disease progression in adults with ALS, ${ }^{13}$ although others have found conflicting results. ${ }^{45}$

\section{Improving the Diagnosis of Metabolic Myopathies}

Although earlier studies suggest that muscle ultrasound has lower sensitivity in detecting metabolic myopathies compared with structural myopathies and muscular dystrophies in children, more recent studies show that muscle ultrasound can still be clinically useful, for example, in the diagnosis of Pompe disease due to acid-maltase deficiency, or by showing muscle changes in other glycogen storage diseases. ${ }^{46}$ In one study, muscle ultrasound showed focal abnormalities affecting the deeper layers of biceps brachii, with relative sparing of the triceps brachii; more severe involvement of the vastus intermedius in comparison with the rectus femoris was also reported in adults with Pompe disease. ${ }^{47}$ Vill et $\mathrm{al}^{48}$ did not find a selective pattern of muscle vulnerability in patients with Pompe disease; instead, they reported that bone echogenicity was less attenuated even in advance stages of the disease, and muscle ultrasound was used as a screening tool for adults (but not in infants) with late-onset disease. More recently, Hwang et $\mathrm{al}^{49}$ advocated for the use of semi-quantitative muscle ultrasound as a diagnostic tool to help discriminate between neonates with low acid alpha-glucosidase activity related to infantile or late-onset Pompe disease; the sensitivity of muscle ultrasound was reported as $100 \%$ (CI $69.2 \%-100 \%$ ) and the specificity was $84 \%$ (CI 63.9\%-95.5\%). 
(a)

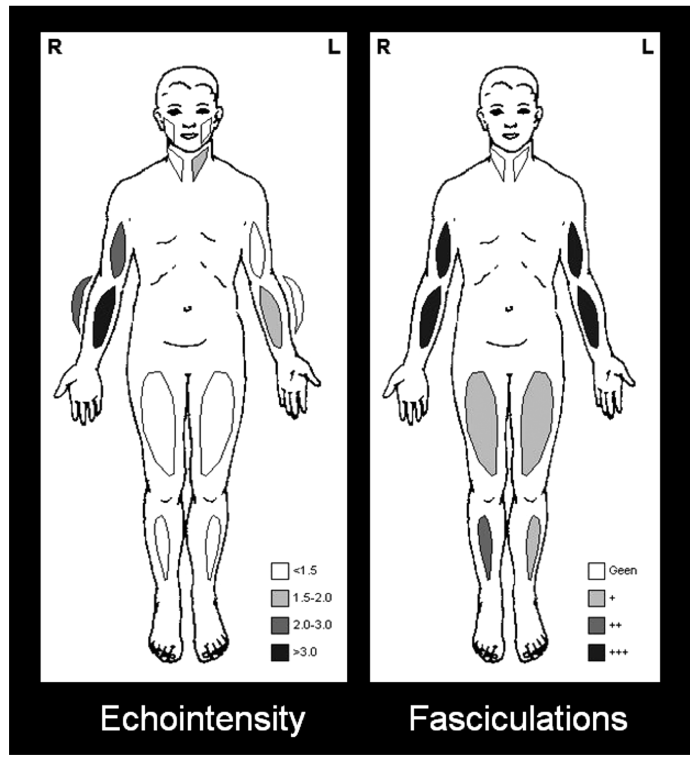

(b)

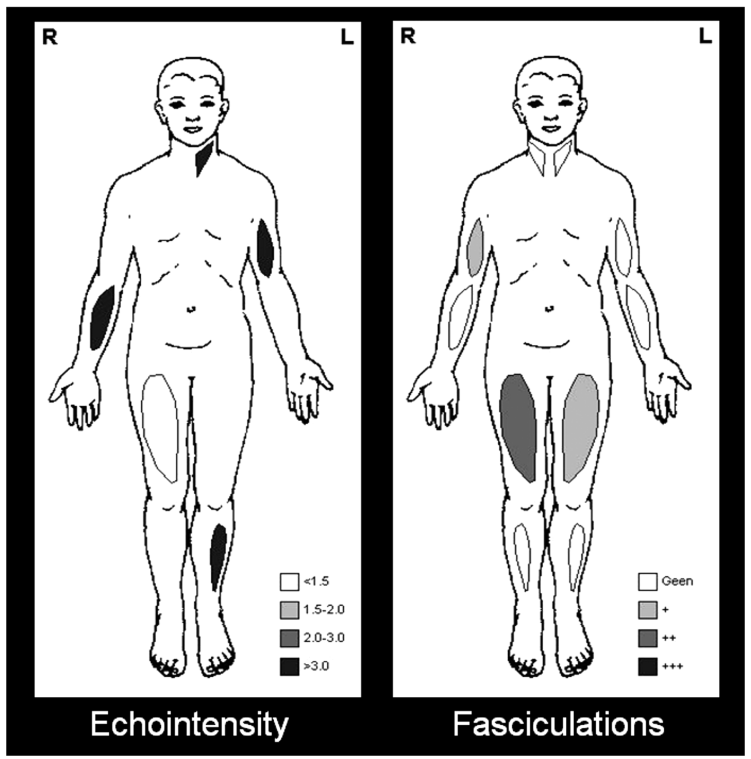

Figure 7: Example of muscle ultrasound showing different pattern of involvement in amyotophic lateral sclerosis (ALS) versus ALS mimics. (a) ALS, with mild to moderately increased echo intensity, diffuse fasciculations, and atrophy of paretic muscles; (b) Inclusion body myositis, with severely increased echo intensity, either none or some fasciculations, and pronounced atrophy.

\section{Guiding Needle Placement}

Ultrasound has been used increasingly to guide botulinum toxin injections and other bedside treatment procedures. ${ }^{50,51}$ For the treatment of spasticity and dystonia with botulinum toxin, ultrasound guidance has been shown to improve clinical outcomes, ${ }^{52,53}$ and ultrasound-guided needle muscle biopsy offers a viable alternative to open biopsy for the diagnosis of neuromuscular diseases, with comparable tissue samples results. ${ }^{54}$ Ultrasound can help determine the optimal muscle biopsy site; the use of tissue Doppler evaluation before and after the biopsy can also help minimize potential complications by avoiding vessels and nerves ${ }^{54}$ Furthermore, ultrasound can be used to guide needle EMG to distinguish muscles in close proximity, ${ }^{55}$ and to enhance patient safety when needling the diaphragm, ${ }^{56}$ the periscapular muscles, ${ }^{57}$ or other muscles in patients on anticoagulants. ${ }^{58}$ In a cadaveric study, ultrasound greatly improved needle EMG placement accuracy in most muscles. ${ }^{59}$ As well, a recent review showed that ultrasound guidance increased the success rates of lumbar puncture and reduced the procedural time in patients with poorly palpable landmarks related to obesity, prior spinal surgery, and other difficult clinical circumstances. ${ }^{60}$ Further studies are needed to determine whether ultrasound may facilitate the delivery of novel disease-modifying treatment such as intrathecal injections for patients with SMA.

\section{Assessing Muscles that Cannot be Easily Accessed with EMG}

Dysphagia is a common symptom in patients with neuromuscular diseases. A recent systematic review of dysphagia in children focused primarily on boys with DMD; there was a lack of widely accepted screening or evaluation protocol for other pediatric neuromuscular disorders. ${ }^{61}$ Boys with DMD were found to have (a)

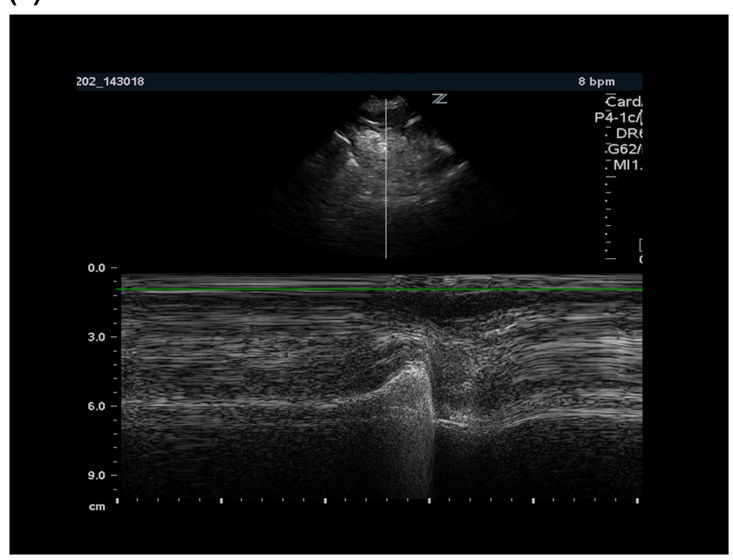

(b)

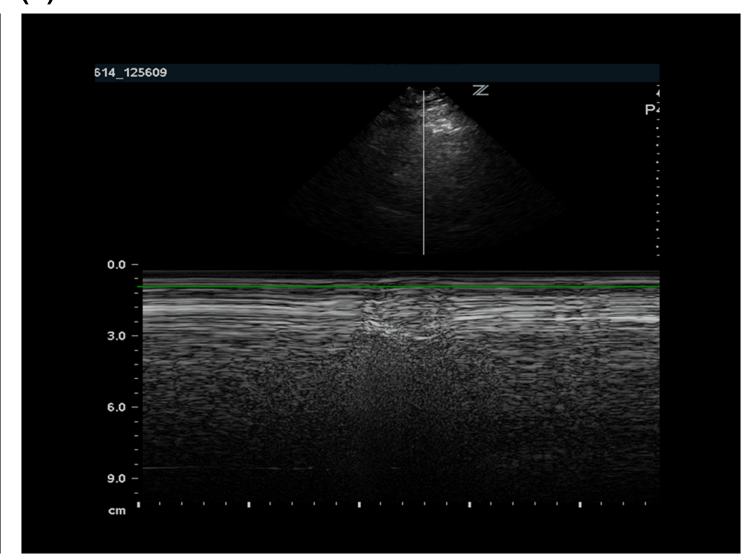

Figure 8: Dysphagia evaluation using Motion mode (M-mode) ultrasound of the tongue while swallowing 5 ml of water. (a) Healthy control showing clearly defined phases of tongue movement; (b) Young adult male with Duchenne muscular dystrophy showing minimal tongue movement due to severe weakness. 
progressive involvement of the oropharyngeal muscles, necessitating the modification of feeding strategies to minimize dysphagia. ${ }^{62}$ As transporting and swallowing requires the use of more than 25 pairs of oral and masticatory muscles that are difficult to be assessed by EMG, van den Engel-Hoek et $\mathrm{al}^{63}$ proposed to use muscle ultrasound as a standard diagnostic tool for the assessment of dysphagia (Figures 8A-8B), based on their extensive experience with ultrasound in the neuromuscular population.

As well, ultrasound can be used as a non-invasive diagnostic test to determine the functional status of facial muscles, and to help identify ideal candidates for facial nerve reconstruction surgery even after an extended period of denervation. ${ }^{64,65}$

Patients in the intensive care unit (ICU) are at risk of developing critical illness neuromuscular disorders. Traditionally, the clinical history, physical exam, and electrophysiological evaluations such as EMG and nerve conduction study are essential for the diagnosis of critical illness neuromyopathy; however, these assessments may be limited by a lack of patient cooperation due to sedation or encephalopathy, electrical interference, treatment with anticoagulants, or other confounding factors in the ICU. Therefore, Cartwright et $\mathrm{al}^{66}$ proposed that serial quantitative ultrasound can be used to study ICUacquired weakness and muscle atrophy, without requiring patient cooperation. However, more recent studies suggest that ultrasound has difficulty detecting early changes (less than 2 weeks) in muscles of patients with ICU-acquired weakness, and the reliability of muscle ultrasound in this disorder is not fully established. ${ }^{67-68}$ In a recent review, Ong et $\mathrm{al}^{69}$ summarized the limitations of ultrasound, including a substantial intra-rater variability in quadriceps MT that resulted in its low reliability and accuracy as a marker for critical illness neuromyopathy in the pediatric population. The diagnostic utility of ultrasound in this clinical context remains undefined.

In contrast to evaluating ICU-acquired weakness, ultrasound is an ideal non-invasive bedside procedure for the detection of early neuromuscular diaphragmatic dysfunction of any cause, with a sensitivity of $93 \%$ and a specificity of $100 \% .^{70,71}$

\section{Biomarker for Treatment Trials}

A longitudinal observational study of 18 boys with DMD showed high correlations of increasing muscle echogenicity with disease progression and functional status. ${ }^{11}$ As well, among 5 young boys (age 0.5-2.8 years) with DMD, there was evidence of disease progression with increased muscle EI over 2.5 years, despite functional improvements during early childhood, ${ }^{72}$ quantitative muscle ultrasound by backscatter or grayscale analysis from superficial regions of muscles provided comparable measures of disease pathology in this population. ${ }^{73}$ More recently, Zaidman et al ${ }^{15}$ examined 36 ambulatory boys (age 2-14 years) with DMD for up to 2 years; the authors found that ultrasound was more sensitive in detecting clinical deterioration in DMD than motor functional assessments, including the 6-minute walk test or the supine-to-stand test. Boys with DMD showed significant increases in muscle EI due to progressive fibro-fatty tissue replacement (Figure 9); the changes were significant as early as 6 months from baseline for boys less than 7 years old, and at 12 months for boys 7 years or older when compared with age- and gender-matched healthy controls. ${ }^{15}$ Therefore, muscle ultrasound may serve as a potential biomarker for disease progression as well as a non-invasive outcome measure in multicenter drug trial for DMD, without requiring patient cooperation. ${ }^{74}$

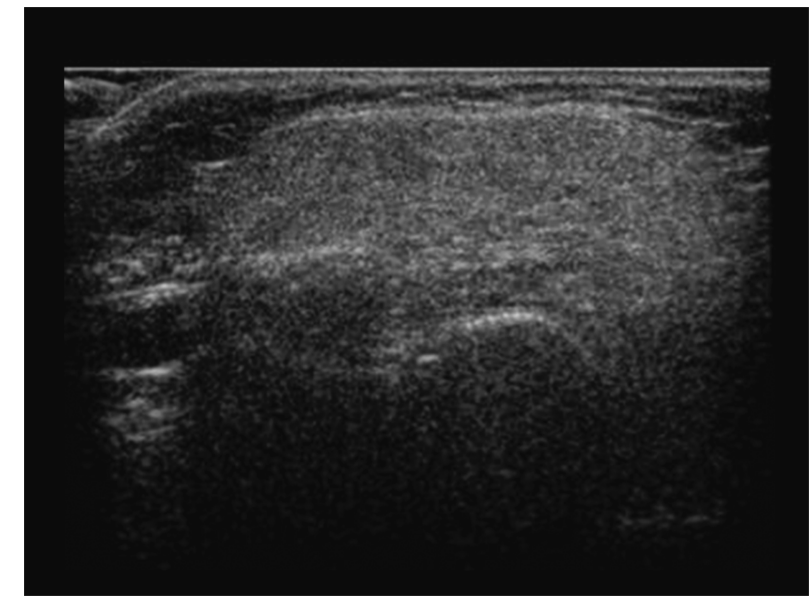

Figure 9: Abnormal transverse axis quadriceps muscle ultrasound in a child with Duchenne muscular dystrophy; diffuse fibro-fatty tissue replacement in this disorder is shown with increased echogenicity, leading to a "ground glass" appearance.

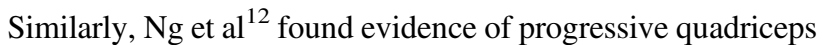
atrophy and increased muscle EI in three infants with SMA type 1 at 2-4 months after initial assessments (Figure 10). The rapid decline in ultrasound measures was consistent with the severe phenotype of early onset SMA; ultrasound could potentially be used as a biomarker for disease progression and to determine responsiveness to new emerging treatment for this disease. ${ }^{12}$

\section{Practical Uses of Nerve Ultrasound}

High-resolution ultrasound has been helpful in the evaluation of genetic and acquired neuropathies, as recently reviewed by a number of leading experts. ${ }^{13,56,75}$ Ultrasound offers superior spatial resolution and ability to detect subtle structural abnormalities in peripheral nerves through the availability of high-frequency (12-18 MHz) transducers, advances in image processing, and sensitive Doppler technology. ${ }^{76}$

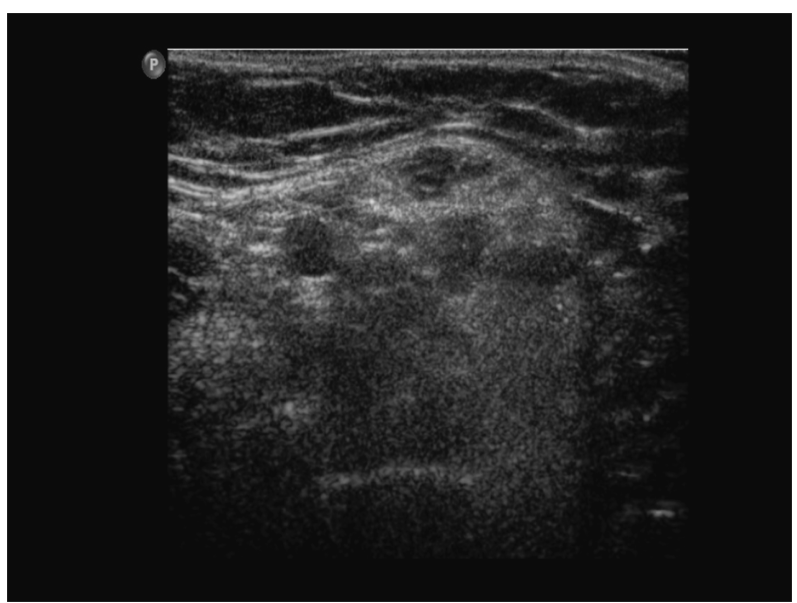

Figure 10: Abnormal transverse quadriceps muscle ultrasound in a child with spinal muscular atrophy. The image shows increased subcutaneous fatty tissue, and a "moth-eaten" appearance representing areas of denervated atrophic fibers versus reinnervated, hypertrophic muscle fibers (the "moth holes"). 
Common clinical applications of nerve ultrasound include screening for entrapment, diagnosing genetic and acquired neuropathies, complementing EMG in the assessment of nerve trauma, surveying for tumor progression, and providing precise landmark for nerve injections. In experienced hands, ultrasound is more sensitive than MRI (93\% vs. 67\%) and has a comparable specificity $(86 \%)$ for detecting peripheral nerve pathology. ${ }^{19}$ As well, ultrasound examination was able to identify degenerative or post-traumatic changes, soft-tissue masses, and other distinct extraneural findings in nearly one-quarter of patients without peripheral nerve abnormalities; many of these patients benefited from the additional evaluation of these extraneural findings. ${ }^{77}$

\section{Screening for Nerve Entrapment}

Peripheral nerve injury leads to a number of anatomical changes, including altered dimension, echogenicity, and vascularity. In nerve entrapment syndromes, there may be focal areas of nerve enlargement just proximal to the site of the compression, with associated loss of the internal fascicular architecture, and reduction in nerve echogenicity. ${ }^{78}$ Ultrasound has been helpful in confirming the precise anatomic localization of the injury, assessing for nerve continuity, as well as identifying other structural changes in a number of neuromuscular conditions.

\section{Carpal Tunnel Syndrome (CTS)}

Median mononeuropathy across the wrist is the most common type of nerve entrapment, and it has been studied extensively with the use of ultrasound (Figures 11A-11B). ${ }^{79}$ A systemic review confirmed that the accuracy of ultrasound is comparable to EMG and nerve conduction studies for the diagnosis of CTS; based on a median nerve cross-sectional area (CSA) cut-off value of $8.5 \mathrm{~mm}^{2}$ to $10 \mathrm{~mm}^{2}$, Cartwright et al ${ }^{10}$ concluded that ultrasound had an overall sensitivity of $65 \%$ to $97 \%$, a specificity of $72.7 \%$ to $98 \%$, and a PPV of $79 \%$ to $97 \%$ for the diagnosis of CTS. A greater than $40 \%$ increase in nerve size from the forearm to carpal tunnel was also found to be suspect for entrapment in patients with CTS, ${ }^{80}$ but later studies have emphasized that the CSA itself remains the most robust measure to confirm the disorder. ${ }^{81}$ Scanning the whole carpal tunnel instead of just the proximal inlet increased the sensitivity by $15 \%$ to $20 \% .{ }^{82,83}$ Additionally, as ultrasound can detect other anatomic abnormality such as a ganglion cyst or accessory muscle, the authors concluded that ultrasound provides additional value to electrodiagnostic studies when assessing patients with CTS. ${ }^{10}$ The use of tissue Doppler plus standard

(a)
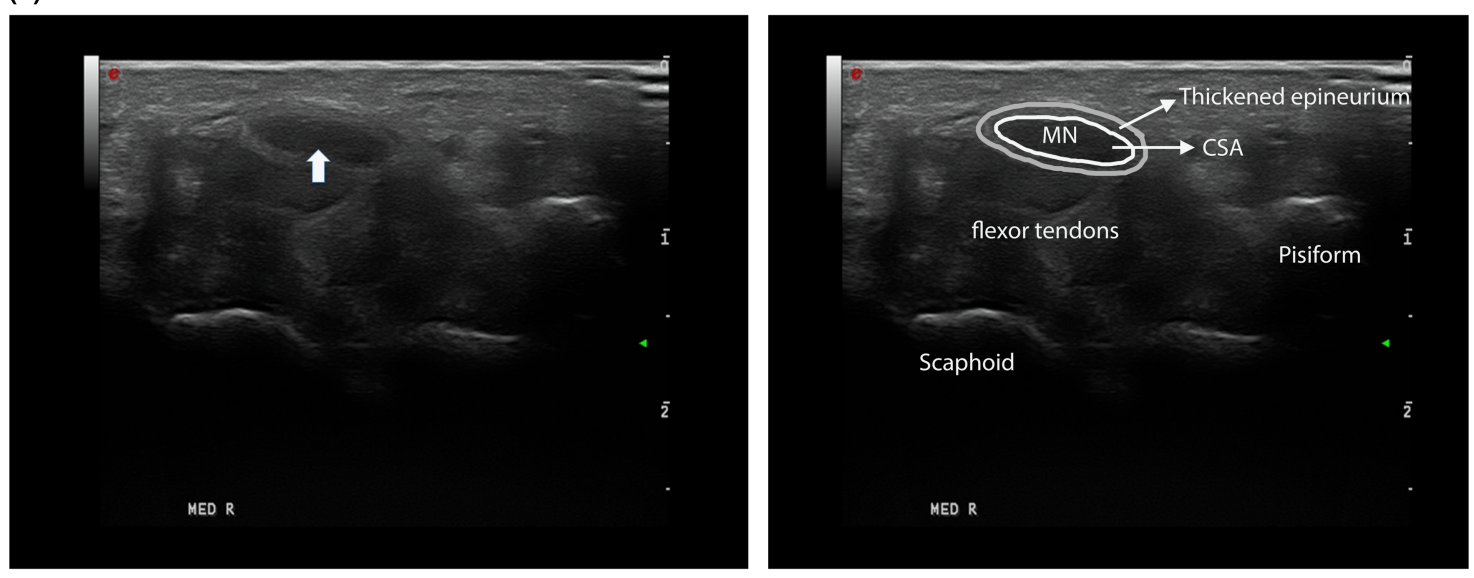

(b)

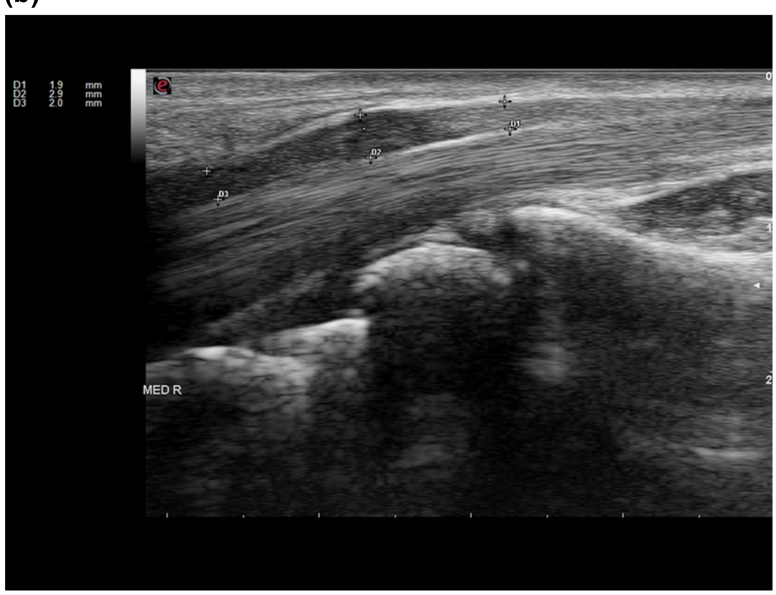

Figure 11: An example of a patient with Carpel tunnel syndrome. (a) Right median nerve in short axial view, with a crosssectional area (CSA) of $17 \mathrm{~mm}^{2}$ (see arrow), normal $<11 \mathrm{~mm}^{2}$. (b) Same nerve in longitudinal view showing focal nerve enlargement (marked by arrows) just proximal to notching caused by compression of the carpal ligament. 


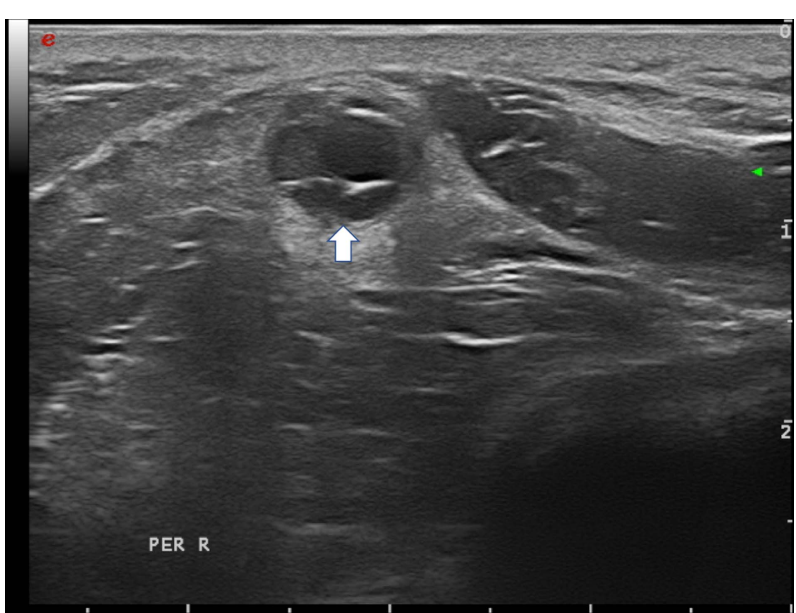

Figure 12: Fibular nerve with intraneural ganglion cyst (arrow); the hypoechoic cystic areas can be seen on the right, while the displaced fascicles are on the left side in the nerve.

ultrasound parameters may help confirm the diagnosis plus identify optimal treatment and improve surgical outcomes for CTS. ${ }^{79,81}$

\section{Other Entrapment Syndromes}

Other entrapment syndromes including ulnar neuropathy at the elbow or wrist, and fibular neuropathy at the knee (Figure 12) can be evaluated according to specific nerve ultrasound study protocol. ${ }^{78}$ As well, ultrasound has been useful for the diagnosis of meralgia paresthetica $^{84}$ and neurogenic thoracic outlet syndrome. ${ }^{85}$

\section{Neuropathy in Hereditary Diseases}

A recent cross-sectional study showed that nerve ultrasound is a useful screening tool for CTS in children with mucopolysaccharidosis type 1, 2 and 6, with higher (92\%) sensitivity than EMG $(77 \%)$ or clinical exam $(26 \%)$ alone. ${ }^{86}$ One year post carpal tunnel release surgery, there was improvement in the median distal motor latencies and compound motor action potential (CMAP) amplitudes; however, the median nerve CSA at the wrist and the wrist to forearm ratio remained unchanged. ${ }^{86}$ As well, ultrasound was able to detect multifocal nerve enlargement in two siblings with neuropathies secondary to mucolipidosis type 3 ; electrophysiological studies were normal in both patients apart from distal median neuropathies. ${ }^{87}$

Beyond the diagnosis of entrapment syndromes in lysosomal storage diseases, ultrasound has been used to assist with the diagnosis of hereditary neuropathies. Among the genetic neuropathies, CharcotMarie-Tooth type 1A (CMT1A) is one of the most prevalent subtypes. It is an autosomal dominant inherited demyelinating motor and sensory polyneuropathy caused by duplication of the PMP22 gene. In patients with genetically confirmed CMT1A, ultrasound revealed uniformed nerves enlargement, with significantly increased CSA of the nerve roots, brachial plexus, and peripheral nerves, compared with those in healthy subjects and patients with CMT type $2 .^{76,88}$ Ultrasound may be particularly helpful in CMT type 1 patients with hypertrophic nerves and absent CMAP response due to distal muscle atrophy, or an inability to tolerate nerve conduction study due to the need for high stimulation intensity. ${ }^{76,88}$ An increase in nerve CSA is also seen disproportionately in children with $\mathrm{CMT}^{8} \mathrm{~A}^{89}$ and other demyelinating CMT subtypes. ${ }^{90,91}$

In addition, hereditary neuropathy with liability to pressure palsy (HNPP) due to a deletion of the PMP22 gene is associated with focal nerve enlargement at common entrapment sites, ${ }^{92}$ whereas non-inflammatory axonal neuropathies generally show normal nerve sizes. ${ }^{93,94}$ Loewenbrück et al further proposed the use of diagnostic ultrasound models to discriminate between demyelinating and axonal forms of CMT; they reported high sensitivity (84\%-100\%) and specificity (86\%-100\%) with ultrasound, especially for the axonal CMT subtypes. ${ }^{95,96}$ Therefore, a combination of clinical exam, electrodiagnostic study, and nerve ultrasound may provide important clues for targeted gene testing.

Similarly, nerve ultrasound has been used to elucidate peripheral nerve involvement in Friedreich ataxia, autosomal dominant spinocerebellar ataxia, plus other cerebellar ataxia with neuropathy syndromes. ${ }^{97-99}$

\section{Diagnosis of Other Neuropathies}

As summarized below, nerve ultrasound can aid in confirming the diagnosis of inflammatory neuropathies, nerve tumors, and traumatic nerve injuries; it can also be used in the evaluation of small fiber polyneuropathy. ${ }^{100}$ A polyneuropathy screen generally includes an examination of standard ultrasound muscles, with the addition of distal muscles such as the peroneus tertius, first dorsal interosseous, and other clinically affected muscles (see Figure 1C), as well as ultrasound scanning of common peripheral (median, ulnar, fibular, and tibial) nerves, plus proximal brachial plexus and nerve roots as clinically indicated.

\section{Acquired Inflammatory Neuropathies}

Acute (AIDP) or chronic (CIDP) inflammatory demyelinating polyneuropathy is associated with patchy enlargement of the peripheral nerves and nerve roots that can be visualized by ultrasound. ${ }^{76,101,102}$ In one study of AIDP, multifocal nerve enlargements with increased CSA were seen within 3 weeks after the onset of symptoms, with sonographic improvement after treatment 3 months later. ${ }^{103}$ Another recent study provided class II evidence that a compact nerve ultrasound protocol with scanning of bilateral median nerves and brachial plexus has high positive and NPV (100\% and $98 \%$, respectively) for discriminating CIDP, Lewis-Sumner syndrome, and MMN from other clinical mimics. ${ }^{104}$ Thus nerve ultrasound may be used in conjunction with the clinical exam and electrophysiology to distinguish between different types of acquired demyelinating neuropathies and to optimize treatment plans.

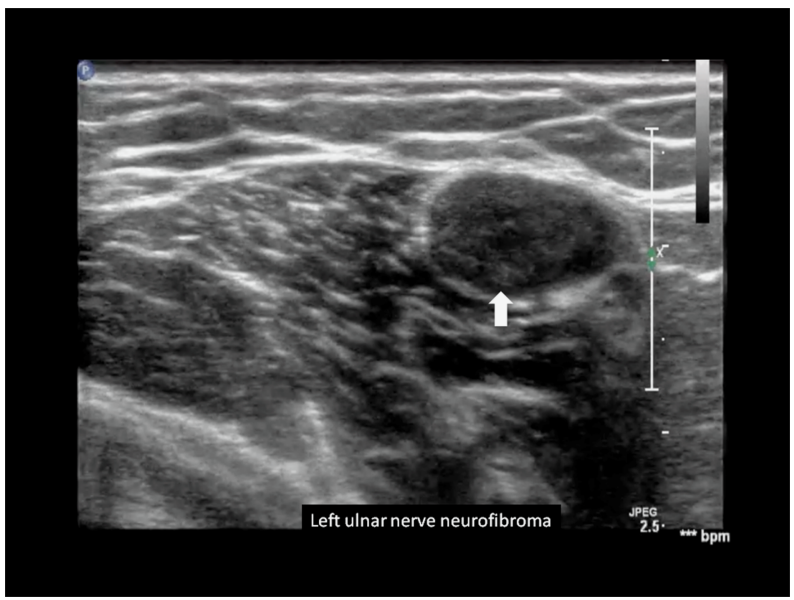

Figure 13: Left ulnar nerve with neurofibroma, marked by the arrow. 
Table 2: Examples of diagnostic values of ultrasound in specific neuromuscular disorders

\begin{tabular}{|c|c|c|c|c|c|c|}
\hline $\begin{array}{l}\text { Type of } \\
\text { neuromuscular } \\
\text { disease (NMD) }\end{array}$ & $\begin{array}{c}\text { Age } \\
\text { range (in } \\
\text { years) }\end{array}$ & $\begin{array}{c}\text { Number } \\
\text { of } \\
\text { patients }\end{array}$ & $\begin{array}{l}\text { Methods of ultrasound } \\
\text { assessment }\end{array}$ & Sensitivity & Specificity & Comments \\
\hline \multicolumn{7}{|l|}{ General screen } \\
\hline $\begin{array}{l}\text { Pillen et al } \\
(2003)^{20}\end{array}$ & $0.5-14$ & 36 & $\begin{array}{l}\text { Quantitative, muscle EI } \\
\text { and MT }\end{array}$ & $92 \%$ & $90 \%$ & Quantitative muscle US can detect NMD in children \\
\hline $\begin{array}{l}\text { Pillen et al } \\
(2006)^{23}\end{array}$ & $0-18$ & 76 & $\begin{array}{l}\text { Visual vs. } \\
\text { quantitative }\end{array}$ & $\begin{array}{l}71 \% \\
87 \%\end{array}$ & $\begin{array}{l}92 \% \\
67 \%\end{array}$ & Quantitative method is more objective and accurate \\
\hline $\begin{array}{l}\text { Pillen et al } \\
(2007)^{21}\end{array}$ & $0-18$ & 150 & $\begin{array}{c}\text { Quantitative } \\
\text { Overall } \\
\text { Neurogenic } \\
\text { Myopathic }\end{array}$ & $\begin{array}{l}71 \% \\
67 \% \\
\text { NA }\end{array}$ & $\begin{array}{l}91 \% \\
94 \% \\
\text { NA }\end{array}$ & Sensitivity is lower in children $<3$ years, with $25 \%$ false-negative rate \\
\hline $\begin{array}{l}\text { Brockmann et al } \\
(2007)^{30}\end{array}$ & $0-18$ & 134 & $\begin{array}{c}\text { Semi-quantitative } \\
\text { Overall } \\
\text { Myopathic } \\
\text { Neurogenic }\end{array}$ & $\begin{array}{l}81 \% \\
67 \% \\
77 \% \\
\end{array}$ & $\begin{array}{l}96 \% \\
92 \% \\
98 \%\end{array}$ & $\begin{array}{l}\text { Overall sensitivity, specificity, and accuracy was lower in children } \leq 3 \\
\text { years old, and in mitochondrial diseases }\end{array}$ \\
\hline $\begin{array}{l}\text { Brandsma et al } \\
(2014)^{26}\end{array}$ & $0-7$ & 100 & $\begin{array}{l}\text { Visual, muscle echoden- } \\
\text { sity and homogeneity }\end{array}$ & $85 \%$ & $75 \%$ & Overall higher specificity in experienced observer ( $86 \%$ vs. $69 \%$ ) \\
\hline $\begin{array}{l}\text { ICU-acquired } \\
\text { weakness (ICU- } \\
\text { AW) } \\
\text { Witteveen et al } \\
(2017)^{68}\end{array}$ & $\begin{array}{l}\text { Median } \\
\quad 60\end{array}$ & 71 & $\begin{array}{c}\text { Quantitative, MT, EI, } \\
\text { homogeneity, nerve size, } \\
\text { and CSA }\end{array}$ & $3 \%-46 \%$ & $67 \%-97 \%$ & $\begin{array}{l}\text { A single neuromuscular US exam is not able to reliably diagnose } \\
\text { ICU-AW in ICU patients early in the disease }\end{array}$ \\
\hline \multicolumn{7}{|l|}{ Myopathy } \\
\hline $\begin{array}{l}\text { Muscular } \\
\text { dystrophies, all }\end{array}$ & & & & & & \\
\hline $\begin{array}{l}\text { Heckmatt et al } \\
(1988)^{125}\end{array}$ & $0-18$ & 66 & Semi-quantitative & $76 \%$ & NA & Higher false negatives in preclinical cases \\
\hline $\begin{array}{l}\text { DMD } \\
\text { Weng et al } \\
(2017)^{123}\end{array}$ & $2-24$ & 47 & $\begin{array}{l}\text { Quantitative, US Naka- } \\
\text { gami imaging of lower } \\
\text { limb muscles }\end{array}$ & $76 \%$ & $95 \%$ & $\begin{array}{l}\text { Changes in the Nakagami parameter correlated with severity and } \\
\text { functional decline in boys with DMD }\end{array}$ \\
\hline $\begin{array}{l}\text { Myotonic } \\
\text { disorders } \\
\text { Abraham et al } \\
(2018)^{126}\end{array}$ & $17-60$ & 16 & $\begin{array}{l}\text { Quantitative thenar mus- } \\
\text { cles relaxation time }\end{array}$ & $88 \%$ & $100 \%$ & $\begin{array}{l}\text { A cut-off of }>0.9 \text { was used for myotonia detection; relaxation time } \\
\text { did not correlate with severity }\end{array}$ \\
\hline $\begin{array}{l}\text { Congenital } \\
\text { myopathies } \\
\text { Heckmatt et al } \\
(1988)^{125}\end{array}$ & $0-9$ & 7 & Semi-quantitative & $57 \%$ & NA & In myopathy the muscle thickness is usually preserved \\
\hline $\begin{array}{l}\text { Metabolic } \\
\text { myopathies, all } \\
\text { Heckmatt et al } \\
(1988)^{125}\end{array}$ & $0.5-14$ & 4 & Semi-quantitative & $50 \%$ & NA & US can show selective muscle involvement within the quadriceps \\
\hline $\begin{array}{l}\text { Mitochondrial } \\
\text { myopathies } \\
\text { Pillen et al } \\
(2006)^{23}\end{array}$ & $1-15$ & 53 & Quantitative & $25 \%-46 \%$ & $85 \%-100 \%$ & $\begin{array}{l}\text { US is not ideal as a screening test for young children with metabolic } \\
\text { myopathies }\end{array}$ \\
\hline $\begin{array}{l}\text { Acid-maltase } \\
\text { deficiency } \\
\text { Hwang et al } \\
(2017)^{49}\end{array}$ & $0.1-2.5$ & 35 & Semi-quantitative & $100 \%$ & $84 \%$ & $\begin{array}{l}\text { US is a good screening tool for newborns with suspected Pompe } \\
\text { disease }\end{array}$ \\
\hline $\begin{array}{l}\text { Inflammatory } \\
\text { myopathies } \\
\text { Reimers et al } \\
(1993)^{127}\end{array}$ & $21-82$ & 70 & $\begin{array}{l}\text { Visual and } \\
\text { quantitative }\end{array}$ & $83 \%$ & NA & US improved clinical assessment for myositis \\
\hline $\begin{array}{l}\text { Inclusion body } \\
\text { myositis (IBM) } \\
\text { Noto et al } \\
(2014)^{128}\end{array}$ & $68-79$ & 18 & $\begin{array}{l}\text { Quantitative, forearm } \\
\text { FDP-FCU EI contrast }\end{array}$ & $100 \%$ & NA & Selective involvement of FDP in sporadic IBM \\
\hline \multicolumn{7}{|l|}{ Neuropathy } \\
\hline $\begin{array}{l}\text { Polyneuropathy } \\
\text { (PN): CMT } \\
\text { Heckmatt et al } \\
(1988)^{125}\end{array}$ & $2-16$ & 8 & Semi-quantitative & $63 \%$ & NA & Distal lower extremities muscles more affected in CMT \\
\hline
\end{tabular}


Table 2. Continued

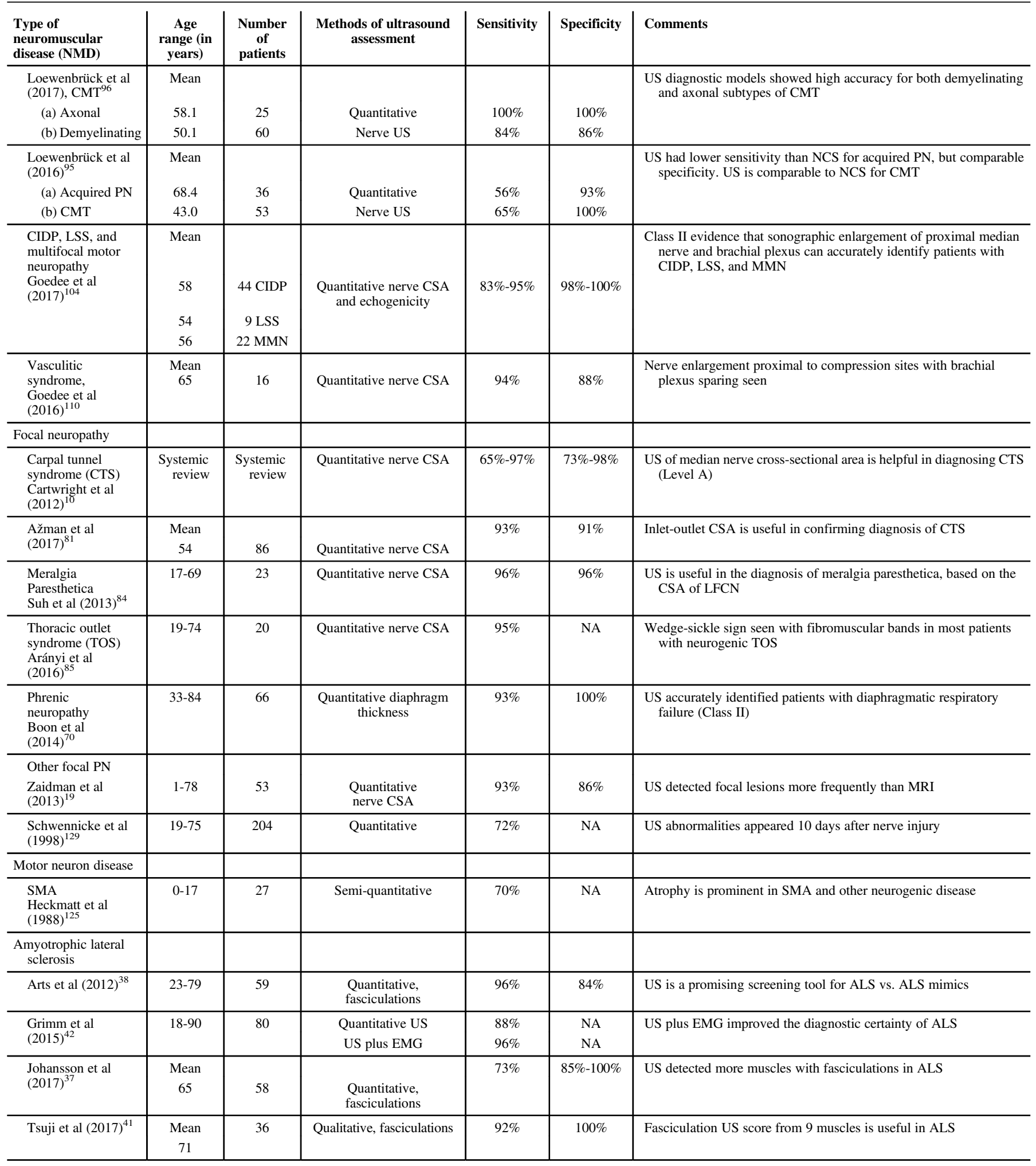


Table 2. Continued

\begin{tabular}{|c|c|c|c|c|c|c|}
\hline $\begin{array}{l}\text { Type of } \\
\text { neuromuscular } \\
\text { disease (NMD) }\end{array}$ & $\begin{array}{c}\text { Age } \\
\text { range (in } \\
\text { years) }\end{array}$ & $\begin{array}{c}\text { Number } \\
\text { of } \\
\text { patients }\end{array}$ & $\begin{array}{l}\text { Methods of ultrasound } \\
\text { assessment }\end{array}$ & Sensitivity & Specificity & Comments \\
\hline \multirow{3}{*}{$\begin{array}{l}\text { ALS vs. MMN } \\
\text { Grimm et al } \\
(2015)^{43}\end{array}$} & & & & & & $\begin{array}{l}\text { Enlarged nerves/roots in } 4 \text { or more areas serve to differentiate MMN } \\
\text { from ALS }\end{array}$ \\
\hline & 65.6 & 17 ALS & Quantitative & $87 \%$ & $94 \%$ & \\
\hline & 55.6 & $8 \mathrm{MMN}$ & Nerve US & & & \\
\hline \multirow{3}{*}{$\begin{array}{l}\text { Loewenbrïck et al } \\
\qquad(2016)^{44}\end{array}$} & Mean & & & & & Nerve US is highly accurate in differentiating between ALS and MMN \\
\hline & 53.6 & $5 \mathrm{MMN}$ & Quantitative & $100 \%$ & $92 \%$ & \\
\hline & 65.1 & $8 \mathrm{ALS}$ & Nerve CSA & & & \\
\hline
\end{tabular}

$\mathrm{ALS}=$ amyotrophic lateral sclerosis; $\mathrm{CIDP}=$ chronic inflammatory demyelinating polyneuropathy; $\mathrm{CMT}=\mathrm{Charcot}-\mathrm{Marie}-\mathrm{Tooth}$ disease; $\mathrm{CSA}=$ crosssectional area; $\mathrm{DMD}=$ Duchenne muscular dystrophy; EI=echointensity; $\mathrm{EMG}=$ electromyography; FCU = flexor carpi ulnaris; FDP = flexor digitorum profundus; IBM = inclusion body myositis; ICU = intensive care unit; $\mathrm{LFCN}=$ lateral femoral cutaneous nerve; $\mathrm{LSS}=\mathrm{Lewis-Sumner} \mathrm{Syndrome;} \mathrm{MMN} \mathrm{=}$ multifocal motor neuropathy; MT = muscle thickness; NA = not available; NCS = nerve conduction study; PN= polyneuropathy; SMA = spinal muscular atrophy; US = ultrasound.

In neuralgic amyotrophy, nerve inflammation with enlarged CSA can be seen involving the brachial plexus as well as peripheral nerves in the distal upper arm. ${ }^{105-108}$ Focal nerve enlargement can also at times be demonstrated by ultrasound in other axonal inflammatory disorders such as sarcoid neuropathy ${ }^{109}$ and neuropathy associated with vasculitis syndromes. ${ }^{110}$

\section{Neurofibromatosis and Neurolymphomatosis}

Ultrasound has been used to detect early or subclinical peripheral nerve involvement in neurofibromatosis type 1 (NF1) and 2 (NF2). Affected nerves show focal areas of gross hypoechoic enlargement of the various fascicles. Isolated focal enlargement constitute a localized neurofibroma, while multiple serpentine-like affected fascicles are seen in a plexiform neurofibroma. The abnormalities often extend over long segments of the main limb nerves and can also occur in skin nerve branches (Figure 13). ${ }^{11-113}$

As well, in a recent case report of three adults with lymphoma and clinical evidence of focal neuropathy, nerve ultrasound was helpful in identifying lymphomatous peripheral nerve infiltration or neurolymphomatosis that was subsequently confirmed by biopsy. ${ }^{114}$ Therefore, ultrasound may be beneficial for peripheral nerve tumor surveillance in patients with neurofibromatosis and possibly neurolymphomatosis. ${ }^{115}$

\section{Traumatic Nerve Injuries}

Ultrasound has also been used to assess patients with focal nerve injuries, including infants with obstetrical brachial plexopathy and adults with acquired peripheral nerve or brachial plexus trauma. ${ }^{16-117}$ Pillen et al $^{118}$ recently showed that the cervical roots, brachial plexus, and proximal nerves can be visualized by ultrasound as early as the neonatal period, and reference data are available from their standardized nerve ultrasound protocol. As well, Smith et al $^{119}$ reported on the utility of ultrasound for patients with combat-related peripheral nerve injuries, in addition to standard clinical, EMG, and MRI exams. In their study, ultrasound was superior to electrodiagnostic test in the ability to clearly demonstrate the specific site of focal nerve involvement among four adults post gunshot or blasts injuries with non-excitable nerve responses; the location was later confirmed by surgical inspection. 119

\section{Injections for Entrapment Neuropathies}

Ultrasound provides clear anatomic landmarks for steroids injections as part of the treatment for entrapment neuropathies; ${ }^{120}$ in addition, it can be used to determine the clinical response to treatment. Lee et al found a significant reduction in the median nerve CSA starting 1-week post injection for CTS; changes in ultrasound parameters correlated with patient-reported improvement in pain scores. ${ }^{121}$

\section{Diagnostic Values of Ultrasound in Neuromuscular DISORDERS}

A summary of the diagnostic values for ultrasound in specific myopathies, neuropathies, and motor neuron disorders is provided in Table 2. In experienced hands, ultrasound is a sensitive and specific tool for the detection of many neuromuscular disorders, and it can also be used as a screening tool among children with suspected peripheral nervous system diseases. It is not well suited as a general screening test for metabolic myopathies, and the utility of ultrasound may be reduced in young children under 3 years of age. $^{23,30}$ Alternative methods using texture analysis and acoustic structural quantification of sonographic images may further increase the diagnostic utility of ultrasound for many patients with neuromuscular diseases. ${ }^{122,123}$

\section{Conclusion}

This review has focused on the clinical applications of nerve and muscle ultrasound. It has shown that neuromuscular ultrasound can provide added diagnostic values in both adult and pediatric neurology practice. Ultrasound can be used as a point-ofcare and patient-friendly screening tool for many peripheral nervous system disorders, and it may obviate the need for more invasive testing. It is expected that over the next 5-10 years, neuromuscular ultrasound will play a definitive role in the diagnostic workup for many of these patients.

\section{ACKNOWLEDGMENTS}

The authors thank their colleague Dr. Sigrid Pillen for her contributions to the artwork. 


\section{DisClOSURES}

The authors have nothing to disclose.

\section{Statement of Authorship}

JKM analyzed the literature and drafted the manuscript; NvA performed the literature search, critically revised the manuscript for content and provided the images.

\section{REFERENCES}

1. Hawley RJ Jr, Schellinger D, O'Doherty DS. Computed tomographic patterns of muscles in neuromuscular diseases. Arch Neurol. 1984;41(4):383-7.

2. Marconi G, Mahjneh I, Pizzi A. Muscle CT in peripheral neuropathies. Acta Neurol Scand. 2001;104(3):156-61.

3. Swash M, Brown MM, Thakkar C. CT muscle imaging and the clinical assessment of neuromuscular disease. Muscle Nerve. 1995; 18(7):708-14

4. Stoll G, Wilder-Smith E, Bendszus M. Imaging of the peripheral nervous system. Handb Clin Neurol. 2013;115:137-53.

5. Simon NG, Noto YI, Zaidman CM. Skeletal muscle imaging in neuromuscular disease. J Clin Neurosci. 2016;33:1-10.

6. ten Dam L, van der Kooi AJ, Verhamme C, Wattjes MP, de Visser M. Muscle imaging in inherited and acquired muscle diseases. Eur J Neurol. 2016;23(4):688-703.

7. Leung DG. Magnetic resonance imaging patterns of muscle involvement in genetic muscle diseases: a systematic review. J Neurol. 2017;264(7):1320-33.

8. Damon BM, Li K, Bryant ND. Magnetic resonance imaging of skeletal muscle disease. Handb Clin Neurol. 2016;136:827-42.

9. Chhabra A, Madhuranthakam AJ, Andreisek G. Magnetic resonance neurography: current perspectives and literature review. Eur Radiol. 2018;28(2):698-707.

10. Cartwright MS, Hobson-Webb LD, Boon AJ, et al. American Association of Neuromuscular and Electrodiagnostic Medicine. Evidence-based guideline: neuromuscular ultrasound for the diagnosis of carpal tunnel syndrome. Muscle Nerve. 2012;46(2): 287-93.

11. Jansen M, van Alfen N, Nijhuis van der Sanden MW, van Dijk JP, Pillen S, de Groot IJ. Quantitative muscle ultrasound is a promising longitudinal follow-up tool in Duchenne muscular dystrophy. Neuromuscul Disord. 2012;22(4):306-17.

12. Ng KW, Connolly AM, Zaidman CM. Quantitative muscle ultrasound measures rapid declines over time in children with SMA type 1. J Neurol Sci. 2015;358(1-2):178-82.

13. Shen J, Cartwright MS. Neuromuscular ultrasound in the assessment of polyneuropathies and motor neuron disease. J Clin Neurophysiol. 2016;33(2):86-93.

14. Zaidman CM, van Alfen N. Ultrasound in the assessment of myopathic disorders. J Clin Neurophysiol. 2016;33(2):103-11.

15. Zaidman CM, Wu JS, Kapur K, et al. Quantitative muscle ultrasound detects disease progression in Duchenne muscular dystrophy. Ann Neurol. 2017;81(5):633-40.

16. Cartwright MS, Demar S, Griffin LP, Balakrishnan N, Harris JM, Walker FO. Validity and reliability of nerve and muscle ultrasound. Muscle Nerve. 2013;47(4):515-21.

17. Rahmani N, Mohseni-Bandpei MA, Vameghi R, Salavati M, Abdollahi I. Application of ultrasonography in the assessment of skeletal muscles in children with and without neuromuscular disorders: a systematic review. Ultrasound Med Biol. 2015;41 (9):2275-83.

18. Hellmann M, von Kleist-Retzow JC, Haupt WF, Herkenrath P, Schauseil-Zipf U. Diagnostic value of electromyography in children and adolescents. J Clin Neurophysiol. 2005;22(1):43-8.

19. Zaidman CM, Seelig MJ, Baker JC, Mackinnon SE, Pestronk A. Detection of peripheral nerve pathology: comparison of ultrasound and MRI. Neurology. 2013;80(18):1634-40.

20. Pillen S, Scholten RR, Zwarts MJ, Verrips A. Quantitative skeletal muscle ultrasonography in children with suspected neuromuscular disease. Muscle Nerve. 2003;27(6):699-705.
21. Pillen S, Verrips A, van Alfen N, Arts IM, Sie LT, Zwarts MJ. Quantitative skeletal muscle ultrasound: diagnostic value in childhood neuromuscular disease. Neuromuscul Disord. 2007;17 (7):509-16

22. Scholten RR, Pillen S, Verrips A, Zwarts MJ. Quantitative ultrasonography of skeletal muscles in children: normal values. Muscle Nerve. 2003;27(6):693-8.

23. Pillen S, Morava E, Van Keimpema M, et al. Skeletal muscle ultrasonography in children with a dysfunction in the oxidative phosphorylation system. Neuropediatrics. 2006;37 (3):142-7.

24. Maurits NM, Bollen AE, Windhausen A, De Jager AE, Van Der Hoeven JH. Muscle ultrasound analysis: normal values and differentiation between myopathies and neuropathies. Ultrasound Med Biol. 2003;29(2):215-25.

25. Maurits NM, Beenakker EAC, van Schaik DEC, Fock JM, Van Der Hoeven JH. Muscle ultrasound in children: normal values and application to neuromuscular disorders. Ultrasound Med Biol. 2004;30(8):1017-27.

26. Brandsma R, Verbeek RJ, Maurits NM, et al. Visual screening of muscle ultrasound images in children. Ultrasound Med Biol. 2014;40(10):2345-51.

27. Gutmann L. AAEM minimonograph \#46: neurogenic muscle hypertrophy. Muscle Nerve. 1996;19(7):811-8.

28. Reimers CD, Schlotter B, Eicke BM, Witt TN. Calf enlargement in neuromuscular diseases: a quantitative ultrasound study in 350 patients and review of the literature. J Neurol Sci. 1996;143 $(1-2): 46-56$

29. Bönnemann CG, Brockmann K, Hanefeld F. Muscle ultrasound in bethlem myopathy. Neuropediatrics. 2003;34(6):335-6.

30. Brockmann K, Becker P, Schreiber G, Neubert K, Brunner E, Bönnemann C. Sensitivity and specificity of qualitative muscle ultrasound in assessment of suspected neuromuscular disease in childhood. Neuromuscul Disord. 2007;17(7):517-23.

31. Wattjes MP, Kley RA, Fischer D. Neuromuscular imaging in inherited muscle diseases. Eur Radiol. 2010;20(10):2447-60.

32. Trip J, Pillen S, Faber CG, van Engelen BG, Zwarts MJ, Drost G. Muscle ultrasound measurements and functional muscle parameters in non-dystrophic myotonias suggest structural muscle changes. Neuromuscul Disord. 2009;19(7):462-7.

33. Tieleman AA, Vinke A, van Alfen N, van Dijk JP, Pillen S, van Engelen BG. Skeletal muscle involvement in myotonic dystrophy type 2. A comparative muscle ultrasound study. Neuromuscul Disord. 2012;22(6):492-9.

34. Reimers CD, Ziemann U, Scheel A, Rieckmann P, Kunkel M, Kurth C. Fasciculations: clinical, electromyographic, and ultrasonographic assessment. J Neurol. 1996;243(8):579-84.

35. Arts IM, van Rooij FG, Overeem S, et al. Quantitative muscle ultrasonography in amyotrophic lateral sclerosis. Ultrasound Med Biol. 2008;34(3):354-61

36. Misawa S, Noto Y, Shibuya K, et al. Ultrasonographic detection of fasciculations markedly increases diagnostic sensitivity of ALS. Neurology. 2011;77(16):1532-7.

37. Johansson MT, Ellegaard HR, Tankisi H, Fuglsang-Frederiksen A, Qerama E. Fasciculations in nerve and muscle disorders - a prospective study of muscle ultrasound compared to electromyography. Clin Neurophysiol. 2017;128(11):2250-7.

38. Arts IM, Overeem S, Pillen S, et al. Muscle ultrasonography: a diagnostic tool for amyotrophic lateral sclerosis. Clin Neurophysiol. 2012;123(8): 1662-7.

39. Noto YI, Shibuya K, Shahrizaila N, et al. Detection of fasciculations in amyotrophic lateral sclerosis: the optimal ultrasound scan time. Muscle Nerve. 2017;56(6):1068-71.

40. O'Gorman CM, Weikamp JG, Baria M, et al. Detecting fasciculations in cranial nerve innervated muscles with ultrasound in amyotrophic lateral sclerosis. Muscle Nerve. 2017;56(6):1072-6.

41. Tsuji Y, Noto YI, Shiga K, Teramukai S, Nakagawa M, Mizuno T. A muscle ultrasound score in the diagnosis of amyotrophic lateral sclerosis. Clin Neurophysiol. 2017;128(6):1069-74.

42. Grimm A, Prell T, Décard BF, et al. Muscle ultrasonography as an additional diagnostic tool for the diagnosis of amyotrophic lateral sclerosis. Clin Neurophysiol. 2015;126(4):820-7. 
43. Grimm A, Décard BF, Athanasopoulou I, Schweikert K, Sinnreich M, Axer H. Nerve ultrasound for differentiation between amyotrophic lateral sclerosis and multifocal motor neuropathy. J Neurol. 2015;262(4):870-80.

44. Loewenbrïck KF, Liesenberg J, Dittrich M, et al. Nerve ultrasound in the differentiation of multifocal motor neuropathy (MMN) and amyotrophic lateral sclerosis with predominant lower motor neuron disease (ALS/LMND). J Neurol. 2016;263(1):35-44.

45. Arts IM, Overeem S, Pillen S, Schelhaas HJ, Zwarts MJ. Muscle changes in amyotrophic lateral sclerosis: a longitudinal ultrasonography study. Clin Neurophysiol. 2011;122(3):623-8.

46. Verbeek RJ, Sentner CP, Smit GP, et al. Muscle ultrasound in patients with glycogen storage disease types I and III. Ultrasound Med Biol. 2016;42(1):133-42.

47. Zaidman CM, Malkus EC, Siener C, Florence J, Pestronk A, AlLozi M. Qualitative and quantitative skeletal muscle ultrasound in late-onset acid maltase deficiency. Muscle Nerve. 2011;44 (3):418-23

48. Vill K, Schessl J, Teusch V, et al. Muscle ultrasound in classic infantile and adult Pompe disease: a useful screening tool in adults but not in infants. Neuromuscul Disord. 2015;25(2):120-6.

49. Hwang HE, Hsu TR, Lee YH, Wang HK, Chiou HJ, Niu DM. Muscle ultrasound: a useful tool in newborn screening for infantile onset Pompe disease. Medicine (Baltimore). 2017;96(44): e8415.

50. Davidson J, Jayaraman S. Guided interventions in musculoskeletal ultrasound: what's the evidence? Clin Radiol. 2011;66(2):140-52.

51. Walter U, Dressler D. Ultrasound-guided botulinum toxin injections in neurology: technique, indications and future perspectives. Expert Rev Neurother. 2014;14(8):923-36.

52. Santamato A, Micello MF, Panza F, et al. Can botulinum toxin type A injection technique influence the clinical outcome of patients with post-stroke upper limb spasticity? A randomized controlled trial comparing manual needle placement and ultrasound-guided injection techniques. J Neurol Sci. 2014;347(1-2):39-43.

53. Grigoriu AI, Dinomais M, Rémy-Néris O, Brochard S. Impact of injection-guiding techniques on the effectiveness of botulinum toxin for the treatment of focal spasticity and dystonia: a systematic review. Arch Phys Med Rehabil. 2015;96(11):206778.e1.

54. O'Sullivan PJ, Gorman GM, Hardiman OM, Farrell MJ, Logan PM. Sonographically guided percutaneous muscle biopsy in diagnosis of neuromuscular disease. J Ultrasound Med. 2006;25(1):1-6.

55. Wininger YD, Buckalew NA, Kaufmanan RA, Munin MC. Ultrasound combined with electrodiagnosis improves lesion localization and outcome in posterior interosseous neuropathy. Muscle Nerve. 2015;52(6):1117-21.

56. Boon AJ, O'Gorman C. Ultrasound in the assessment of respiration. J Clin Neurophysiol. 2016;33(2):112-9.

57. Krzesniak-Swinarska M, Caress JB, Cartwright MS. Neuromuscular ultrasound for evaluation of scapular winging. Muscle Nerve. 2017;56(1):7-14.

58. Boon A. Ultrasonography and electrodiagnosis: are they complementary techniques. PM R. 2013;5(5 Suppl.):S100-6.

59. Yun JS, Chung MJ, Kim HR, et al. Accuracy of needle placement in cadavers: non-guided versus ultrasound-guided. Ann Rehabil Med. 2015;39(2):163-9.

60. Soni NJ, Franco-Sadud R, Schnobrich D, et al. Ultrasound guidance for lumbar puncture. Neurol Clin Pract. 2016;6(4):358-68.

61. Audag N, Goubau C, Toussaint M, Reychler G. Screening and evaluation tools of dysphagia in children with neuromuscular diseases: a systematic review. Dev Med Child Neurol. 2017;59 (6):591-6.

62. van den Engel-Hoek L, Erasmus CE, Hendriks JC, et al. Oral muscles are progressively affected in Duchenne muscular dystrophy: implications for dysphagia treatment. J Neurol. 2013;260 (5):1295-303

63. van den Engel-Hoek L, Harding C, van Gerven M, Cockerill H. Pediatric feeding and swallowing rehabilitation: an overview. J Pediatr Rehabil Med. 2017;10(2):95-105.

64. van Alfen N, Gilhuis HJ, Keijzers JP, Pillen S, van Dijk JP. Quantitative facial muscle ultrasound: feasibility and reproducibility. Muscle Nerve. 2013;48(3):375-80.
65. Volk GF, Pohlmann M, Sauer M, Finkensieper M, Guntinas-Lichius O. Quantitative ultrasonography of facial muscles in patients with chronic facial palsy. Muscle Nerve. 2014;50(3):358-65.

66. Cartwright MS, Kwayisi G, Griffin LP, et al. Quantitative neuromuscular ultrasound in the intensive care unit. Muscle Nerve. 2013;47(2):255-9.

67. Bunnell A, Ney J, Gellhorn A, Hough CL. Quantitative neuromuscular ultrasound in intensive care unit-acquired weakness: a systematic review. Muscle Nerve. 2015;52(5):701-8.

68. Witteveen E, Sommers J, Wieske L, et al. Diagnostic accuracy of quantitative neuromuscular ultrasound for the diagnosis of intensive care unit-acquired weakness: a cross-sectional observational study. Ann Intensive Care. 2017;7(1):40.

69. Ong C, Lee JH, Leow MKS, Puthucheary ZA. Skeletal muscle ultrasonography in nutrition and functional outcome assessment of critically ill children: experience and insights from pediatric disease and adult critical care studies. J Parenter Enteral Nutr. 2017;41(7):1091-9.

70. Boon AJ, Sekiguchi H, Harper CJ, et al. Sensitivity and specificity of diagnostic ultrasound in the diagnosis of phrenic neuropathy. Neurology. 2014;83(14):1264.

71. Unbrello M, Formenti P. Ultrasonographic assessment of diaphragm function in critically ill subjects. Respir Care. 2016;61(4):542-55.

72. Zaidman CM, Malkus EC, Connolly AM. Muscle ultrasound quantifies disease progression over time in infants and young boys with Duchenne muscular dystrophy. Muscle Nerve. 2015;52 (3):334-8

73. Shklyar I, Geisbush TR, Mijialovic AS, et al. Quantitative muscle ultrasound in Duchenne muscular dystrophy: a comparison of techniques. Muscle Nerve. 2015;51(2):207-13.

74. Rutkove SB, Kapur K, Zaidman CM, et al. Electrical impedance myography for assessment of Duchenne muscular dystrophy. Ann Neurol. 2017;81(5):622-32.

75. Hobson-Webb LD, Padua L. Ultrasound of focal neuropathies. J Clin Neurophysiol. 2016;33(2):94-102.

76. Gallardo E, Noto Y, Simon NG. Ultrasound in the diagnosis of peripheral neuropathy: structure meets function in the neuromuscular clinic. J Neurol Neurosurg Psychiatry. 2015;86 (10):1066-74

77. Bignotti B, Zaottini F, Airaldi S, Martinoli C, Tagliafico A. Extraneural findings during peripheral nerve ultrasound: prevalence and further assessment. Muscle Nerve. 2018;57(1):65-9.

78. Cartwright MS, Walker FO. Neuromuscular ultrasound in common entrapment neuropathies. Muscle Nerve. 2013;48(5):696-704.

79. Chen YT, Williams L, Zak MJ, Fredericson M. Review of ultrasonography in the diagnosis of carpal tunnel syndrome and a proposed scanning protocol. J Ultrasound Med. 2016;35 (11):2311-24

80. Hobson-Webb LD, Massey JM, Juel VC, Sanders DB. The ultrasonographic wrist-to-forearm median nerve area ratio in carpal tunnel syndrome. Clin Neurophysiol. 2008;119(6):1353-7.

81. Ažman D, Hrabač P, Demarin V. Use of multiple ultrasonographic parameters in confirmation of carpal tunnel syndrome. J Ultrasound Med. 2018;37(4):879-89.

82. Paliwal PR, Therimadasamy AK, Chan YC, Wilder-Smith EP. Does measuring the median nerve at the carpal tunnel outlet improve ultrasound CTS diagnosis? J Neurol Sci. 2014;339(12):47-51.

83. Csillik A, Bereczki D, Bora L, Arányi Z. The significance of ultrasonographic carpal tunnel outlet measurements in the diagnosis of carpal tunnel syndrome. Clin Neurophysiol. 2016;127(12): 3516-3523

84. Suh DH, Kim DH, Park JW, Park BK. Sonographic and electrophysiologic findings in patients with meralgia paresthetica. Clin Neurophysiol. 2013;124(7):1460-4

85. Arányi Z, Csillik A, Böhm J, Schelle T. Ultrasonographic identification of fibromuscular bands associated with neurogenic thoracic outlet syndrome: the "wedge-sickle" sign. Ultrasound Med Biol. 2016;42(10):2357-66.

86. Bäumer T, Bühring N, Schelle T, Münchau A, Muschol N. Nerve ultrasound in clinical management of carpal tunnel syndrome in mucopolysaccharidosis. Dev Med Child Neurol. 2016;58 (11):1172-9. 
87. Mulroy E, Chancellor AM, Pelosi L. Peripheral nerve ultrasound findings in mucolipidosis type 3. Neuroradiology. 2018; 60(2):207-9.

88. Shahrizaila N, Noto Y, Simon NG, et al. Quantitative muscle ultrasound as a biomarker in Charcot-Marie-tooth neuropathy. Clin Neurophysiol. 2017;128(1):227-32.

89. Yiu EM, Brockley CR, Lee KJ, et al. Peripheral nerve ultrasound in pediatric Charcot-Marie-Tooth disease type 1A. Neurology. 2015;84(6):569-74.

90. Noto Y, Shiga K, Tsuji Y, et al. Nerve ultrasound depicts peripheral nerve enlargement in patients with genetically distinct CharcotMarie-Tooth disease. J Neurol Neurosurg Psychiatry. 2015;86 (4):378-84.

91. Luigetti M, Sabatelli M, Bellone E, Fabrizi GM, Padua L, Granata G. Nerve ultrasound in patients with CMT1C: description of 3 cases. Muscle Nerve. 2015;51(5):781-2.

92. Padua L, Coraci D, Lucchetta M, et al. Different nerve ultrasound patterns in Charcot-Marie-Tooth types and hereditary neuropathy with liability to pressure palsies. Muscle Nerve. 2018;57(1):E1823.

93. Zaidman CM, Al-Lozi M, Pestronk A. Peripheral nerve size in normals and patients with polyneuropathy: an ultrasound study. Muscle Nerve. 2009;40(6):960-6.

94. Goedee HS, Brekelmans GJ, van Asseldonk JT, Beekman R, Mess WH, Visser LH. High resolution sonography in the evaluation of the peripheral nervous system in polyneuropathy-a review of the literature. Eur J Neurol. 2013;20(10):1342-51.

95. Loewenbrück KF, Dittrich M, Böhm J, et al. Diagnostic accuracy of nerve ultrasound in hereditary and sporadic non-entrapment neuropathies. J Neurol. 2016;263(11):2196-206.

96. Loewenbrück KF, Dittrich M, Böhm J, et al. Practically applicable nerve ultrasound models for the diagnosis of axonal and demyelinating hereditary motor and sensory neuropathies (HMSN). J Neurol. 2018;265(1):165-77.

97. Mulroy E, Pelosi L, Leadbetter R, et al. Peripheral nerve ultrasound in Friedreich ataxia. Muscle Nerve. 2018;57(5):852-6.

98. Pelosi L, Mulroy E, Rodrigues MJ, Roxburgh RH. Neuronopathy and neuropathy in autosomal dominant spino-cerebellar ataxia (SCA): a preliminary peripheral nerve ultrasound study. Clin Neurophysiol. 2017;128(12):2436-7.

99. Pelosi L, Leadbetter R, Mulroy E, Chancellor AM, Mossman S, Roxburgh R. Peripheral nerve ultrasound in cerebellar ataxia neuropathy vestibular areflexia syndrome (CANVAS). Muscle Nerve. 2017;56(1):160-2.

100. Ebadi H, Siddiqui H, Ebadi S, Ngo M, Breiner A, Bril V. Peripheral nerve ultrasound in small fiber polyneuropathy. Ultrasound Med Biol. 2015;41(11):2820-6.

101. Décard BF, Fladt J, Axer H, Fischer D, Grimm A. Nerve ultrasound in Miller Fisher variant of Guillain-Barré syndrome. Muscle Nerve. 2015;52(6):1106-10.

102. Di Pasquale A, Morino S, Loreti S, Bucci E, Vanacore N, Antonini G. Peripheral nerve ultrasound changes in CIDP and correlations with nerve conduction velocity. Neurology. 2015;84(8):803-9.

103. Razali SNO, Arumugam T, Yuki N, Rozalli FI, Goh KJ, Shahrizaila N. Serial peripheral nerve ultrasound in Guillain-Barré syndrome. Clin Neurophysiol. 2016;127(2):1652-6.

104. Goedee HS, van der Pol WL, van Asseldonk JH, et al. Diagnostic value of sonography in treatment-naive chronic inflammatory neuropathies. Neurology. 2017;88(2):143-51.

105. Lieba-Samal D, Jengojan S, Kasprian G, Wöber C, Bodner G. Neuroimaging of classic neuralgic amyotrophy. Muscle Nerve. 2016;54(6):1079-85.

106. Abraham A, Izenberg A, Dodig D, Bril V, Breiner A. Peripheral nerve ultrasound imaging shows enlargement of peripheral nerves outside the brachial plexus in neuralgic amyotrophy. J Clin Neurophysiol. 2016;33(5):e31-3.

107. Noda Y, Sekiguchi K, Tokuoka H, et al. Ultrasonographic findings of proximal median neuropathy: A case series of suspected distal neuralgic amyotrophy. J Neurol Sci. 2017;377:1-5.
108. ArÁnyi Z, Csillik A, DéVay K, et al. Ultrasonography in neuralgic amyotrophy: Sensitivity, spectrum of findings, and clinical correlations. Muscle Nerve. 2017;56(6):1054-62.

109. Kerasnoudis A, Woitalla D, Gold R, Pitarokoili K, Yoon MS. Sarcoid neuropathy: Correlation of nerve ultrasound, electrophysiological and clinical findings. J Neurol Sci. 2014;347 (1-2):129-36.

110. Goedee HS, van der Pol L, van Asseldonk, et al. Nerve sonography to detect peripheral nerve involvement in vasculitis syndromes. Neurol Clin Pract. 2016;6(4):293-303.

111. Telleman JA, Stellingwerff MD, Brekelmans GJ, Visser LH. Nerve ultrasound: A useful screening tool for peripheral nerve sheath tumors in NF1? Neurology. 2017;88(17):1615-22.

112. Telleman JA, Stellingwerff MD, Brekelmans GJ, Visser LH. Nerve ultrasound shows subclinical peripheral nerve involvement in neurofibromatosis type 2. Muscle Nerve. 2018;57 (2):312-6

113. Winter N, Rattay TW, Axer H, et al. Ultrasound assessment of peripheral nerve pathology in neurofibromatosis type 1 and 2 . Clin Neurophysiol. 2017;128(5):702-6.

114. Vijayan J, Chan YC, Therimadasamy A, Wilder-Smith EP. Role of combined b-mode and doppler sonography in evaluating neurolymphomatosis. Neurology. 2015;85(9):752-5.

115. Briani C, Visentin A, Cavallaro T, et al. Primary neurolymphomatosis as clinical onset of chronic lymphocytic leukemia. Ann Hematol. 2017;96(1):159-61.

116. Gruber H, Glodny B, Galiano K, et al. High-resolution ultrasound of the supraclavicular brachial plexus-can it improve therapeutic decisions in patients with plexus trauma? Eur Radiol. 2007;17 (6):1611-20.

117. Simon NG, Spinner RJ, Kline DG, Kliot M. Advances in the neurological and neurosurgical management of peripheral nerve trauma. J Neurol Neurosurg Psychiatry. 2016;87 (2):198-208.

118. Pillen S, Semmekrot B, Meulstee J, Verrips A, Van Alfen N. Ultrasound of the cervical roots and brachial plexus in neonates. Muscle Nerve. 2015;51(1):35-41.

119. Smith JK, Miller ME, Carroll CG, et al. High-resolution ultrasound in combat-related peripheral nerve injuries. Muscle Nerve. 2016;54(6):1139-44.

120. Strakowski JA. Ultrasound-guided peripheral nerve procedures. Phys Med Rehabil Clin N Am. 2016;27(3):687-715.

121. Lee YS, Choi E. Ultrasonographic changes after steroid injection in carpal tunnel syndrome. Skeletal Radiol. 2017;46 (11):1521-30.

122. Molinari F, Caresio C, Acharya UR, Mookiah MRK, Minetto MA. Advance in quantitative muscle ultrasonography using texture analysis of ultrasound images. Ultrasound Med Biol. 2015;41 (9):2520-32.

123. Weng WC, Tsui PH, Lin CW, et al. Evaluation of muscular changes by ultrasound Nakagami imaging in Duchenne muscular dystrophy. Sci Rep. 2017;7(1):4429.

124. Pillen S, Arts IM, Zwarts MJ. Muscle ultrasound in neuromuscular disorders. Muscle Nerve. 2008;37(6):679-93.

125. Heckmatt JZ, Pier N, Dubowitz V. Real-time ultrasound imaging of muscles. Muscle Nerve. 1988;11(1):56-65.

126. Abraham A, Breiner A, Barnett C, Bril V, Katzberg HD. Quantitative sonographic assessment of myotonia. Muscle Nerve. 2018;57(1):146-9.

127. Reimers CD, Fleckenstein JL, Witt TN, Müller-Felber W, Pongratz DE. Muscular ultrasound in idiopathic inflammatory myopathies of adults. J Neurol Sci. 1993;116(1):82-92.

128. Noto Y, Shiga K, Tsuji Y, et al. Contrasting echogenicity in flexor digitorum profundus-flexor carpi ulnaris: a diagnostic ultrasound pattern in sporadic inclusion body myositis. Muscle Nerve. 2014;49(5):745-8.

129. Schwennicke A, Bargfrede M, Reimers CD. Clinical, electromyographic, and ultrasonographic assessment of focal neuropathies. J Neuroimaging. 1998;8(3):136-43. 